\title{
Propagation of Isotopic Bias and Uncertainty to Criticality Safety Analyses of PWR Waste Packages
}

\section{June 2010}

\author{
Prepared by
}

G. Radulescu 


\section{DOCUMENT AVAILABILITY}

Reports produced after January 1, 1996, are generally available free via the U.S. Department of Energy (DOE) Information Bridge:

Web site: http://www.osti.gov/bridge

Reports produced before January 1, 1996, may be purchased by members of the public from the following source:

National Technical Information Service

5285 Port Royal Road

Springfield, VA 22161

Telephone: 703-605-6000 (1-800-553-6847)

TDD: 703-487-4639

Fax: 703-605-6900

E-mail: info@ntis.fedworld.gov

Web site: http://www.ntis.gov/support/ordernowabout.htm

Reports are available to DOE employees, DOE contractors, Energy Technology Data Exchange (ETDE) representatives, and International Nuclear Information System (INIS) representatives from the following source:

Office of Scientific and Technical Information

P.O. Box 62

Oak Ridge, TN 37831

Telephone: 865-576-8401

Fax: 865-576-5728

E-mail: reports@adonis.osti.gov

Web site: http://www.osti.gov/contact.html

This report was prepared as an account of work sponsored by an agency of the United States Government. Neither the United States government nor any agency thereof, nor any of their employees, makes any warranty, express or implied, or assumes any legal liability or responsibility for the accuracy, completeness, or usefulness of any information, apparatus, product, or process disclosed, or represents that its use would not infringe privately owned rights. Reference herein to any specific commercial product, process, or service by trade name, trademark, manufacturer, or otherwise, does not necessarily constitute or imply its endorsement, recommendation, or favoring by the United States Government or any agency thereof. The views and opinions of authors expressed herein do not necessarily state or reflect those of the United States Government or any agency thereof. 
ORNL/TM-2010/116

Nuclear Science and Technology Division

\title{
PROPAGATION OF ISOTOPIC BIAS AND UNCERTAINTY TO CRITICALITY SAFETY ANALYSES OF PWR WASTE PACKAGES
}

\author{
Author \\ G. Radulescu
}

Date Published: June 2010

Prepared by

OAK RIDGE NATIONAL LABORATORY

Oak Ridge, Tennessee 37831-6283

managed by

UT-BATTELLE, LLC

for the

U.S. DEPARTMENT OF ENERGY

under contract DE-AC05-00OR22725 



\section{CONTENTS}

Page

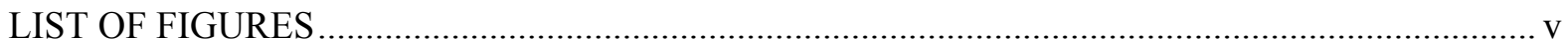

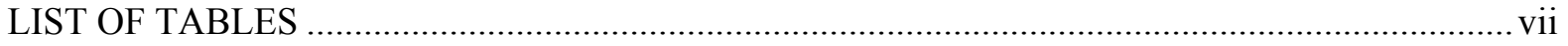

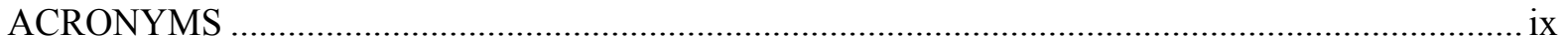

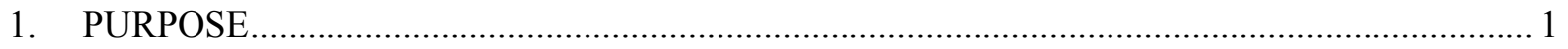

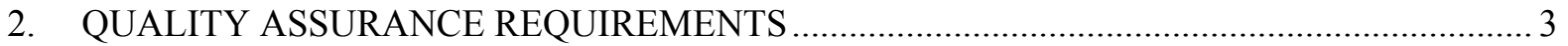

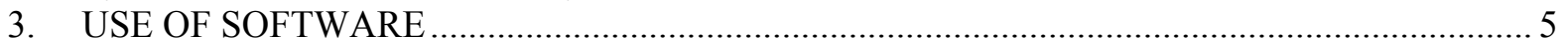

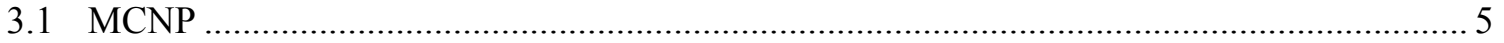

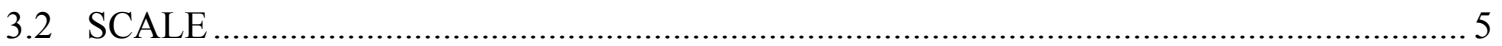

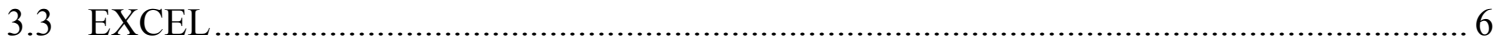

3.4 ORIGIN

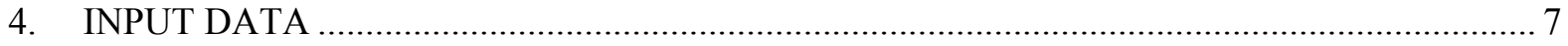

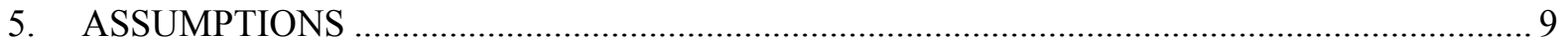

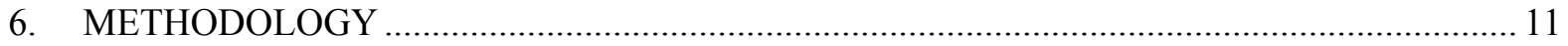

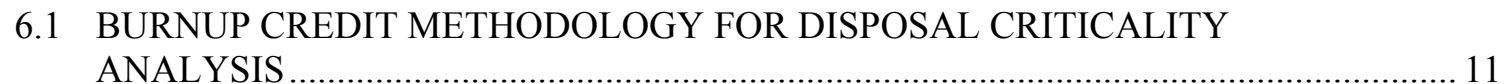

6.2 OVERVIEW OF METHODS FOR DETERMINING THE BIAS AND UNCERTAINTY IN $K_{E F F}$ DUE TO UNCERTAINTY IN THE CALCULATED

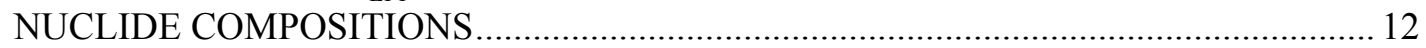

6.3 MONTE CARLO UNCERTAINTY SAMPLING METHOD ........................................... 13

6.3.1 Characterization of the Probability Frequency Distributions Obtained for the Ratio of Measured-to-Calculated Isotopic Concentrations .............................. 13

6.3.2 Application of the Monte Carlo Uncertainty Sampling Method............................. 15

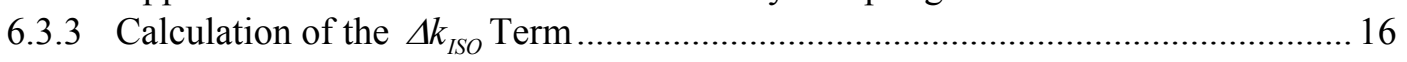

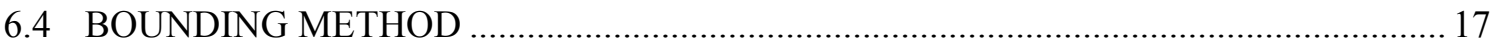

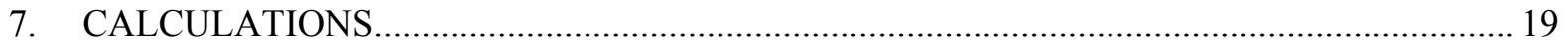

7.1 CALCULATION OF BOUNDING ISOTOPIC COMPOSITIONS FOR PWR

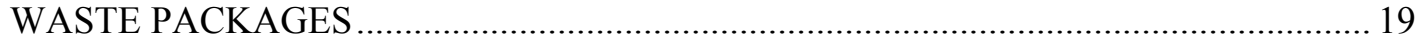

7.1.1 Bounding Assembly Parameters for Depletion Calculations .................................. 19

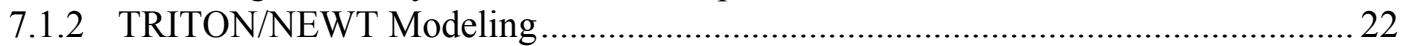

7.2 CHARACTERIZATION OF SCALE 5.1 ISOTOPIC VALIDATION DATA ................... 22

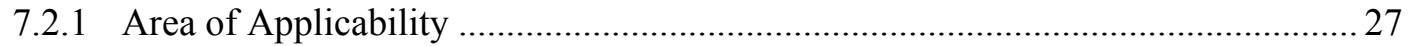

7.3 DESCRIPTION OF THE MCNP MODEL FOR WASTE PACKAGES …....................... 31

7.3.1 Selected Fuel Initial Enrichment, Burnup, and Decay Time for Criticality

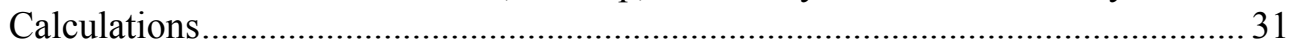

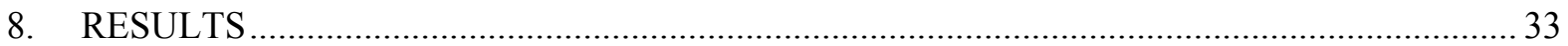

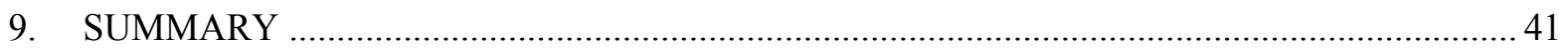

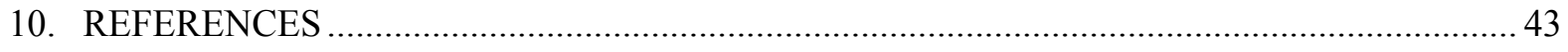

APPENDIX A. STATISTICAL CONCEPTS AND METHODS USED IN VARIOUS

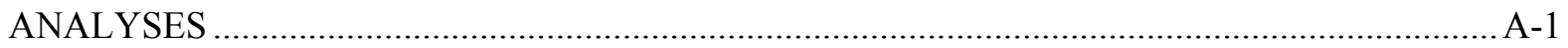

APPENDIX B. VALIDATION OF THE MONTE CARLO UNCERTAINTY

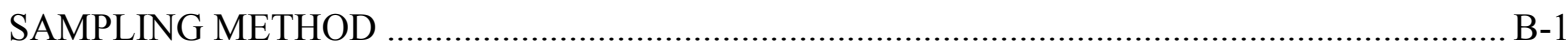

APPENDIX C. ELECTRONIC DATA SPECIFICATIONS ….............................................. 



\section{LIST OF FIGURES}

Figure

1 Fuel pin, guide tube, and instrument tube locations in the B\&W $15 \times 15$ PWR fuel assembly.

TRITON/NEWT geometry representation of the B\&W $15 \times 15$ assembly with BPRs fully inserted.

3 Enrichment and burnup values of the evaluated spent fuel samples compared to the actual and projected spent fuel assembly inventory and typical loading curve for PWR SNF assuming actinide and fission product burnup credit....

$\mathrm{M} / \mathrm{C}$ isotopic concentration ratio as a function of burnup and the sampling interval for ${ }^{235} \mathrm{U}$.

$5 \mathrm{M} / \mathrm{C}$ isotopic concentration ratio as a function of burnup and the sampling interval for ${ }^{240} \mathrm{Pu}$ based on (a) entire set of evaluated spent fuel samples and (b) the set of evaluated spent fuel samples without the samples from TMI-1 assembly NJ05YU. ....... 30

6 Horizontal cross section of the MCNP model for the PWR waste package. Isotopic concentration versus time after discharge for PWR SNF of 5.0-wt $\%{ }^{235} \mathrm{U}$ initial enrichment and 40-GWd/MTU burnup.

B-1 $\quad k_{e f f-M C}$ and $\Delta k_{e f f-M C}$ convergence. ......................................................................... B-5

B-2 $k_{\text {eff }}$ frequency histograms from (a) 500 MCNP cases and (b) from 200 MCNP cases.... B-5 



\section{LIST OF TABLES}

Table

Page

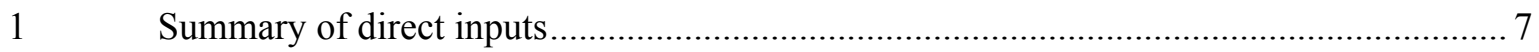

2 Principal isotopes for commercial SNF burnup credit.............................................. 11

3 PWR fuel assembly specifications for isotopic composition calculations ...................... 20

$4 \quad$ Selected enrichment and burnup values for the PWR SNF isotopic database......

Chemical compositions and mass densities for Zircaloy-4 and burnable poison ............. 21

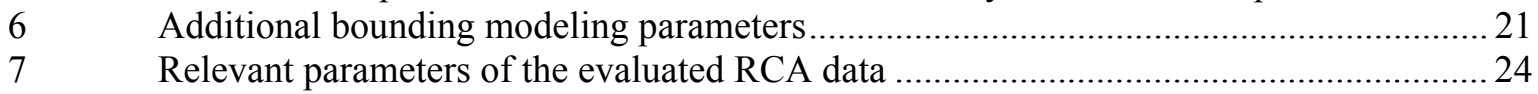

8 Characteristics of the frequency distributions of the $\mathrm{M} / \mathrm{C}$ isotopic concentration

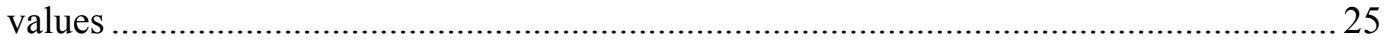

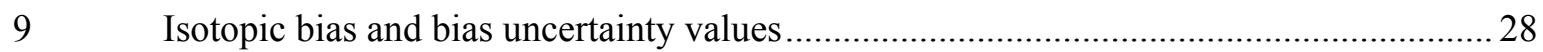

$10 \Delta k_{I S O}$ for waste packages containing PWR SNF at 5 years after discharge .................... 35

$11 \Delta k_{I S O}$ for waste packages containing PWR SNF at 100 years after discharge ................. 37

$12 \Delta k_{I S O}$ for waste packages containing PWR SNF at 10,000 years after discharge ............ 38 



\section{ACRONYMS}

$\begin{array}{ll}\text { 2-D } & \text { two-dimensional } \\ \text { B\&W } & \text { Babcock and Wilcox } \\ \text { BPR } & \text { burnable poison rod } \\ \text { DTN } & \text { data tracking number } \\ \text { DVD } & \text { digital video disc } \\ \text { ENDF } & \text { evaluated nuclear data file } \\ \text { M/C } & \text { measured to calculated } \\ \text { MCNP } & \text { Monte Carlo N-Particle (transport code) } \\ \text { NEWT } & \text { New ESC-based Weighting Transport (code) } \\ \text { NRC } & \text { U.S. Nuclear Regulatory Commission } \\ \text { OCRWM } & \text { Office of Civilian Radioactive Waste Management } \\ \text { ORNL } & \text { Oak Ridge National Laboratory } \\ \text { PWR } & \text { pressurized water reactor } \\ \text { QARD } & \text { quality assurance requirements and description } \\ \text { RCA } & \text { radiochemical assay (data) } \\ \text { S/U } & \text { sensitivity/uncertainty } \\ \text { SCALE } & \text { Standardized Computer Analysis for Licensing Evaluation } \\ \text { SNF } & \text { spent nuclear fuel } \\ \text { TAD } & \text { transport, aging, and disposal } \\ \text { TMI } & \text { Three Mile Island (Unit 1 reactor) } \\ \text { TRITON } & \text { Transport Rigor Implemented with Time-dependent Operation for Neutronic } \\ & \text { depletion (code) } \\ \text { YMP } & \text { Yucca Mountain Project }\end{array}$





\section{PURPOSE}

Burnup credit methodology is economically advantageous because significantly higher loading capacity may be achieved for spent nuclear fuel (SNF) casks based on this methodology as compared to the loading capacity based on a fresh fuel assumption. However, the criticality safety analysis for establishing the loading curve based on burnup credit becomes increasingly complex as more parameters accounting for spent fuel isotopic compositions are introduced to the safety analysis. The safety analysis requires validation of both depletion and criticality calculation methods. Validation of a neutronic-depletion code consists of quantifying the bias and the uncertainty associated with the bias in predicted SNF compositions caused by cross-section data uncertainty and by approximations in the calculational method. The validation is based on comparison between radiochemical assay (RCA) data and calculated isotopic concentrations for fuel samples representative of SNF inventory. The criticality analysis methodology for commercial SNF disposal allows burnup credit for 14 actinides and 15 fission product isotopes in SNF compositions. ${ }^{1}$ The neutronic-depletion method for disposal criticality analysis employing burnup credit is the two-dimensional (2-D) depletion sequence TRITON (Transport Rigor Implemented with Time-dependent Operation for Neutronic depletion)/NEWT (New ESC-based Weighting Transport code) and the 44GROUPNDF5 crosssection library in the Standardized Computer Analysis for Licensing Evaluation (SCALE 5.1) (Ref. 2)

code system. ${ }^{3}$ The SCALE 44GROUPNDF5 cross section library is based on the Evaluated Nuclear Data File/B Version V (ENDF/B-V) library. The criticality calculation code for disposal criticality analysis employing burnup credit is General Monte Carlo N-Particle (MCNP) Transport Code.

The purpose of this calculation report is to determine the bias on the calculated effective neutron multiplication factor, $k_{\text {eff }}$, due to the bias and bias uncertainty associated with predicted spent fuel compositions (i.e., determine the penalty in reactivity due to isotopic composition bias and uncertainty) for use in disposal criticality analysis employing burnup credit. The method used in this calculation to propagate the isotopic bias and bias-uncertainty values to $k_{\text {eff }}$ is the Monte Carlo uncertainty sampling method. ${ }^{5}$

The development of this report is consistent with Test Plan for: Isotopic Validation for Postclosure Criticality of Commercial Spent Nuclear Fuel. ${ }^{6}$ This calculation report has been developed in support of burnup credit activities for the proposed repository at Yucca Mountain, Nevada, and provides a methodology that can be applied to other criticality safety applications employing burnup credit. 



\section{QUALITY ASSURANCE REQUIREMENTS}

Development of this report has been determined to be subject to the Yucca Mountain Project (YMP) quality assurance requirements as described in Test Plan for: Isotopic Validation for Postclosure Criticality of Commercial Spent Nuclear Fuel. ${ }^{6}$ The Test Plan identifies Oak Ridge National Laboratory (ORNL)-Office of Civilian Radioactive Waste Management (OCRWM) quality assurance procedures applicable to the development, documentation, and electronic management of the data for this report.

The development of the calculation and analysis documentation were performed in accordance with ORNL-OCRW-19.1, Calculation Packages. ${ }^{7}$ The Test Plan for the development of the report was prepared in accordance with ORNL-OCRW-21.0, Scientific Investigations. ${ }^{8}$ The control of electronic data was performed in accordance with ORNL-OCRW-23.0, Control of the Electronic Management of Data. ${ }^{9}$ The computer codes used in this calculation have been qualified per ORNL-OCRW-19.0, Software Control. ${ }^{10}$ 



\section{USE OF SOFTWARE}

\subsection{MCNP}

The general-purpose Monte Carlo transport code MCNP was used to calculate the values of neutron multiplication factor, $k_{\text {eff, }}$ for SNF waste packages. The MCNP 5.1.40 code ${ }^{4}$ used herein has been qualified per ORNL-OCRW-19.0, Software Control. ${ }^{10}$

- $\quad$ Software Title: MCNP

- Version/Revision Number: Version 5/Revision 1.40

- Status/Operating System: Qualified/Linux 2.6.9-42.0.2 ELsmp \#1, x86_64 GNU/Linux (Ref. 11)

- Computer Type: CPILE2 Linux cluster of the Nuclear Systems Analysis, Design, and Safety organization, Nuclear Science and Technology Division, ORNL

Rationale for Selection: The MCNP computer code employs the Monte Carlo method to perform radiation transport calculations. The Monte Carlo method stochastically simulates actual physical processes and determines a physical quantity as the expected value of a certain random variable (or combination of several variables). The primary reasons for using this computer code are the following: (1) it is accepted by the U.S. Nuclear Regulatory Commission (NRC) for criticality safety applications, ${ }^{12}$ (2) it allows explicit geometrical modeling of material configurations, and (3) it uses continuous-energy cross sections.

The MCNP $k_{\text {eff }}$ calculations documented in this report used sufficient inactive (300) and active (1000) cycles to obtain convergence of both the $k_{\text {eff }}$ and the fission source distribution before starting active cycles for tallies. The value of estimated $k_{\text {eff }}$ standard deviation for all MCNP calculations was 0.0003. The input and output files for the MCNP calculations are located on a DVD that accompanies this report (refer to Appendix C for the contents of the DVD), so that an independent repetition of the calculations may be performed.

\subsection{SCALE}

The SCALE code system was used to perform transport, depletion, and decay calculations. The SCALE 5.1 code system ${ }^{2}$ used herein has been qualified per ORNL-OCRW-19.0, Software Control. ${ }^{10}$

- Software Title: SCALE

- Version/Revision Number: Version 5.1

- Status/Operating System: Qualified/Linux 2.6.9-42.0.2 ELsmp \#1, x86_64 GNU/Linux (Ref. 13)

- Computer Type: CPILE2 Linux cluster of the Nuclear Systems Analysis, Design, and Safety organization, Nuclear Science and Technology Division, ORNL

Rationale for Selection: SCALE is accepted by the NRC for criticality safety applications. ${ }^{12}$ This computer code system has multiple unique capabilities relevant to this work, including automated sequences to produce problem-dependent multigroup cross-section data and analysis sequences for transport, depletion, and decay calculations.

The input and output files for the SCALE depletion calculations are located on a DVD that accompanies this report (refer to Appendix $C$ for the contents of the DVD), so that an independent repetition of the calculations may be performed. 


\subsection{EXCEL}

The commercial off-the shelf software Microsoft Office Excel 2003 (copyright Microsoft Corporation) was used in calculations to manipulate the inputs and tabulate and chart results using standard mathematical expressions and operations. Excel was used only as a worksheet and not as a software routine. Therefore, Excel is exempt from the requirements of ORNL-OCRW-19.0, Software Control. ${ }^{10}$ All necessary information for reproducing the operations performed is provided on the DVD that accompanies this report so that an independent repetition of the operations may be performed.

\subsection{ORIGIN}

The commercial off-the shelf software OriginPro 8.1 (copyright OriginLab Corporation) was used in calculations to manipulate the inputs and chart results using standard statistical methods and mathematical operations. Origin was used only as a worksheet and not as a software routine. Therefore, Origin is exempt from the requirements of ORNL-OCRW-19.0, Software Control. ${ }^{10}$ All necessary information for reproducing the operations performed is provided on the DVD that accompanies this report so that an independent repetition of the operations may be performed. 


\section{INPUT DATA}

Table 1 provides a summary of the data used as direct inputs to the calculations described in this document, the sources of input data, and a justification for use as direct inputs. Technical input data include YMP qualified data listed by data tracking number (DTN), technical products developed in accordance with Quality Assurance Requirements and Description (QARD), ${ }^{14}$ and information accepted as established fact by the scientific and engineering community.

Table 1. Summary of direct inputs

\begin{tabular}{|c|c|c|c|}
\hline Parameter & Value & Source & Justification \\
\hline $\begin{array}{l}\text { Principal isotopes for commercial } \\
\text { SNF burnup credit }\end{array}$ & See Table 2 & Ref. 1 & $\begin{array}{l}\text { Approved technical product } \\
\text { developed in accordance with } \\
\text { QARD requirements }\end{array}$ \\
\hline $\begin{array}{l}\text { Bounding assembly parameters } \\
\text { for depletion calculations }\end{array}$ & $\begin{array}{l}\text { See Table } 3 \\
\text { and Fig. } 1\end{array}$ & Refs. 15 and 16 & $\begin{array}{l}\text { Approved technical product } \\
\text { developed in accordance with } \\
\text { QARD requirements }\end{array}$ \\
\hline $\begin{array}{l}\text { Zircaloy-4 and burnable poison } \\
\text { material compositions and } \\
\text { densities }\end{array}$ & See Table 5 & Ref. 15 & $\begin{array}{l}\text { Approved technical product } \\
\text { developed in accordance with } \\
\text { QARD requirements }\end{array}$ \\
\hline $\begin{array}{l}\text { Additional bounding parameters } \\
\text { for modeling depletion } \\
\text { conditions }\end{array}$ & See Table 6 & Ref. 15 & $\begin{array}{l}\text { Approved technical product } \\
\text { developed in accordance with } \\
\text { QARD requirements }\end{array}$ \\
\hline $\begin{array}{l}\text { Isotopic composition bias and } \\
\text { bias uncertainty values for the } \\
\text { burnup-credit isotopes }\end{array}$ & See Table 8 & $\begin{array}{l}\text { Ref. } 3 \text { and Ref. } 17 \text { (DTNs: } \\
\text { MO1005PWRSNFIC.000 } \\
\text { and } \\
\text { MO1005RDMALIBU.000) }\end{array}$ & YMP qualified data (Ref. 17) \\
\hline $\begin{array}{l}\text { MCNP model for the pressurized } \\
\text { water reactor (PWR) waste } \\
\text { package with intact assemblies }\end{array}$ & See Sect. 7.3 & $\begin{array}{l}\text { Ref. } 18 \text { (DTN: } \\
\text { MO0711LOADCURV.000) }\end{array}$ & $\begin{array}{l}\text { Approved technical product } \\
\text { developed in accordance with } \\
\text { QARD requirements }\end{array}$ \\
\hline Loading curve parameters & See Sect. 7.3.1 & Ref. 18 & $\begin{array}{l}\text { Approved technical product } \\
\text { developed in accordance with } \\
\text { QARD requirements }\end{array}$ \\
\hline $\begin{array}{l}\text { Minimum cooling time for spent } \\
\text { nuclear fuel }\end{array}$ & 5 years & Ref. 19 (10 CFR 961.11) & $\begin{array}{l}\text { Information accepted as } \\
\text { established fact by scientific } \\
\text { and engineering community }\end{array}$ \\
\hline Tolerance-limit factors & $\begin{array}{l}\text { See } D V D / x l s / \\
\text { validation.xls }\end{array}$ & Refs. 20 and 21 & $\begin{array}{l}\text { Information accepted as } \\
\text { established fact by scientific } \\
\text { and engineering community }\end{array}$ \\
\hline
\end{tabular}





\section{ASSUMPTIONS}

1. It is assumed that the isotopic validation data used in this calculation for each burnup credit isotope form a normal distribution. This assumption facilitates characterization of a probability frequency distribution by the sample mean and sample standard deviation. The rationale for this assumption is that the isotopic validation data are expected to approach the normal distribution as the sample size increases. Currently, a limited number of RCA data are available for use in isotopic validation studies. The statistical characteristics of the isotopic validation data used in this calculation were evaluated in Sect. 7.2.

2. It is assumed that correlations do not exist among the isotopic bias uncertainty values because the bias uncertainty captures the random effects of measurement errors and approximations used in determining modeling parameters that are not well defined, such as moderator density at sample location or effective temperature of the fuel sample. This assumption enables sampling the isotopic bias uncertainty intervals of the burnup credit isotopes independently. The use of tolerance intervals (rather than confidence intervals) to define the range of bias uncertainty is intended to compensate for the effect this assumption may have on the results of the calculations. 



\section{METHODOLOGY}

The biases and bias uncertainties in the SCALE 5.1 predictions for PWR SNF isotopic compositions have been evaluated in Ref. 3 by comparing isotopic concentration values obtained from measurement and calculation for 118 PWR fuel samples. The method employed in the current calculation to propagate the uncertainties in the calculated fuel isotopic composition to the $k_{\text {eff }}$ values for PWR waste packages is the Monte Carlo uncertainty sampling method. This section describes the requirements of burnup credit methodology for disposal criticality analysis and the Monte Carlo uncertainty sampling method and provides an overview of other methods for determining the bias and uncertainty in $k_{\text {eff }}$ due to uncertainty in predicted nuclide compositions.

\subsection{BURNUP CREDIT METHODOLOGY FOR DISPOSAL CRITICALITY ANALYSIS}

Waste package postclosure criticality analysis is based on burnup credit, as described in the Disposal Criticality Analysis Methodology Topical Report. ${ }^{1}$ A set of 29 actinide and fission product isotopes established as being relevant to burnup credit is included in the spent fuel compositions for waste package criticality analyses. The 29 isotopes, which are referred to as principal isotopes for commercial SNF burnup credit in Ref. 1, are listed in Table 2.

Table 2. Principal isotopes for commercial SNF burnup credit

\begin{tabular}{|c|c||c|c|}
\hline \multicolumn{2}{|c||}{ Actinide isotopes } & \multicolumn{2}{c|}{ Fission product isotopes } \\
\hline${ }^{233} \mathrm{U}^{a}$ & ${ }^{239} \mathrm{Pu}$ & ${ }^{95} \mathrm{Mo}$ & ${ }^{149} \mathrm{Sm}$ \\
\hline${ }^{234} \mathrm{U}$ & ${ }^{240} \mathrm{Pu}$ & ${ }^{99} \mathrm{Tc}$ & ${ }^{150} \mathrm{Sm}$ \\
\hline${ }^{235} \mathrm{U}$ & ${ }^{241} \mathrm{Pu}$ & ${ }^{101} \mathrm{Ru}$ & ${ }^{151} \mathrm{Sm}$ \\
\hline${ }^{236} \mathrm{U}$ & ${ }^{242} \mathrm{Pu}$ & ${ }^{103} \mathrm{Rh}$ & ${ }^{152} \mathrm{Sm}$ \\
\hline${ }^{238} \mathrm{U}$ & ${ }^{241} \mathrm{Am}$ & ${ }^{109} \mathrm{Ag}$ & ${ }^{151} \mathrm{Eu}$ \\
\hline${ }^{237} \mathrm{~Np}$ & ${ }^{242 m} \mathrm{Am}$ & ${ }^{143} \mathrm{Nd}$ & ${ }^{153} \mathrm{Eu}$ \\
\hline${ }^{238} \mathrm{Pu}$ & ${ }^{243} \mathrm{Am}$ & ${ }^{145} \mathrm{Nd}$ & \\
\hline
\end{tabular}

Source: Ref. 1.

${ }^{a}$ Although present in negligible concentrations in the current commercial SNF, the ${ }^{233} \mathrm{U}$ isotope will build up from ${ }^{237} \mathrm{~Np}\left(\mathrm{~T}_{1 / 2}=2.410 \mathrm{E}+06\right.$ years) (Ref. 22$)$ to sufficient quantities over long disposal time periods to become a criticality concern.

The disposal criticality analysis methodology requires validation of the models and methods used to determine the $k_{\text {eff }}$ values for waste packages and determination of a critical limit, $C L$ [see Eq. (1)], at which waste package configurations are considered potentially critical. The criticality calculation method for disposal criticality analysis is MCNP (Ref. 23). The depletion calculation method for disposal criticality analysis is TRITON/NEWT (Refs. 24 and 25), which allows for a 2-D explicit representation of assembly heterogeneities, such as control rods, water holes, and burnable poison rods, and the 44GROUPNDF5 (Ref. 26) cross-section library in SCALE 5.1 (Ref. 2). The depletion sequence TRITON/NEWT is validated in this report (see Sect. 7.2) using the results of the isotopic evaluations documented in Ref. 3. 
The critical limit for use in disposal criticality analyses is determined as follows: ${ }^{1}$

$$
C L(x)=f(x)-\Delta k_{E R O A}-\Delta k_{I S O}-\Delta k_{m},
$$

where

$x \quad=$ a neutronic parameter used for trending analysis,

$f(x)=$ the lower bound tolerance limit function accounting for biases and uncertainties that cause the calculation results to deviate from the true value of $k_{\text {eff }}$ for a critical experiment, as reflected over an appropriate set of critical experiments,

$\Delta k_{E R O A}=$ the penalty for extending the range of applicability,

$\Delta k_{I S O}=$ the penalty for isotopic composition bias and uncertainty,

$\Delta k_{m} \quad=$ an arbitrary margin ensuring subcriticality for preclosure and turning the

$C L$ function into an upper subcritical limit function (it is not applicable for use in postclosure analyses because there is no risk associated with a subcritical event).

The term $\Delta k_{I S O}$ in Eq. (1), which is referred to as the penalty for isotopic bias and uncertainty, is determined for PWR SNF waste packages in this calculation report, whereas the lower-bound tolerance limit function for commercial SNF waste packages has been determined in Ref. 23, Range of Applicability and Bias Determination for Postclosure Criticality of Commercial Spent Nuclear Fuel.

\subsection{OVERVIEW OF METHODS FOR DETERMINING THE BIAS AND UNCERTAINTY IN $k_{\text {eff }}$ DUE TO UNCERTAINTY IN THE CALCULATED NUCLIDE COMPOSITIONS}

Methods previously used to determine the bias and uncertainty in $k_{\text {eff }}$ due to uncertainty in the calculated nuclide compositions have included various bounding methods. For example, bounds of no credit to very limited credit for the reduced reactivity potential of irradiated commercial light-water reactor fuel assemblies have been made in criticality analyses and have provided a very conservative safety margin. Best-estimate methods provide for a mathematically derived and more realistic safety margin. ${ }^{27}$ The best-estimate methods include Monte Carlo uncertainty sampling (see Sect. 6.3), direct difference, and cross-section sensitivity/uncertainty $(\mathrm{S} / \mathrm{U})$ analysis methods. The calculations and analysis described in Ref. 27 suggest that the three mentioned best-estimate methods produce similar results in terms of isotopic bias and uncertainty effects on $k_{\text {eff. }}$.

As mentioned in Sect. 6.1, the disposal criticality analysis methodology specifies the use of 29 actinide and fission product isotopes (see Table 2) in spent fuel compositions. A bounding method for determining the bias and uncertainty in $k_{\text {eff }}$ due to uncertainty in the calculated nuclide compositions consists of simultaneously correcting the concentrations of all isotopes relevant to burnup credit for bias and uncertainty in such a way that produces a maximum increase in system reactivity (see Sect. 6.4). In reality, isotopic composition uncertainties have a statistical behavior for most of the burnup-credit isotopes, with both increasing and decreasing effects on system reactivity relative to each other, and the probability for the most unfavorable situation that is specific to the bounding method is extremely small and would not be reproducible in a commercial nuclear power plant. Correlations are not expected to exist among the isotopic bias uncertainty values because the bias uncertainty captures the random effects of measurement errors and approximations used in determining modeling parameters that are not well defined, such as moderator density at sample location or effective temperature of the fuel sample. By averaging such random effects, a bias in calculated isotopic compositions can be obtained. Correlation is expected to exist between the bias of 
an isotope that is almost entirely produced by decay and the bias of their precursors, such as the bias correlation between ${ }^{241} \mathrm{Am}\left(\mathrm{T}_{1 / 2}=432.7\right.$ years $)$ and ${ }^{241} \mathrm{Pu}\left(\mathrm{T}_{1 / 2}=14.4\right.$ years $)$ (Ref. 22). Best-estimate methods supplement the bounding method and provide a more realistic evaluation for the safety margin by crediting compensating effects of isotopic composition uncertainties on $k_{\text {eff. }}$. An assumption associated with the best-estimate methods is that the bias uncertainties for the burnup-credit isotopes are independent variables.

The direct difference method consists of performing criticality calculations for the application system using the measured and calculated isotopic concentrations for the evaluated fuel samples and analyzing the $k_{\text {eff }}$ results associated with the two isotopic composition sets to determine a lower tolerance limit for criticality. Application of this method is appropriate if a comprehensive database of measured fuel isotopic concentrations for all burnup-credit isotopes exists. The direct difference method was employed in Ref. 28 to determine the penalty in reactivity due to the bias and uncertainty associated with SNF isotopic compositions predicted by the one-dimensional depletion analysis code SAS2H in SCALE 4.4a. The direct difference method is not considered in the current calculation because this calculation is being developed to expand on that method by incorporating the individual nuclide uncertainty distributions into the overall bias and uncertainty term.

The cross-section $\mathrm{S} / \mathrm{U}$ analysis method determines the response in $k_{\text {eff }}$ caused by first-order linear perturbations in cross-section data. Since a relative change in the concentration of an isotope has the same effect on $k_{\text {eff }}$ as the same relative change in the microscopic cross section of the isotope, sensitivity coefficients can be used to determine the system $k_{\text {eff }}$ uncertainty caused by uncertainties in the concentrations of individual isotopes. TSUNAMI-3D (Ref. 29), the S/U analysis module in the SCALE code system, may be used to calculate the $k_{\text {eff }}$ sensitivity profiles and coefficients for the burnup-credit isotopes. However, the $\mathrm{S} / \mathrm{U}$ analysis method is not considered in the current calculation because the criticality method in the TSUNAMI-3D calculation sequence is KENO, whereas the criticality method used in waste package postclosure criticality calculations ${ }^{23}$ is MCNP.

\subsection{MONTE CARLO UNCERTAINTY SAMPLING METHOD}

The current calculation uses the Monte Carlo uncertainty sampling method to propagate the values of bias and bias uncertainty associated with predicted fuel isotopic compositions to the $k_{\text {eff }}$ values for waste packages. The characteristics of this method and its implementation are described in this section. Proper implementation of the Monte Carlo uncertainty sampling method is demonstrated in Appendix B.1.

\subsubsection{Characterization of the Probability Frequency Distributions Obtained for the Ratio of Measured-to-Calculated Isotopic Concentrations}

Many classical statistical methods rely on the assumption of normality of the data to make probabilistic inferences from samples to populations. The normal distribution is characterized by two parameters: the arithmetic mean $(\mu)$ and the standard deviation $(\sigma)$. For datasets forming a normal distribution, the arithmetic mean and the standard deviation may be estimated by the sample mean $(\bar{X})$ and the sample standard deviation $(s)$, respectively.

The isotopic composition bias and bias uncertainty values associated with the TRITON/NEWT depletion calculation method in SCALE 5.1 are determined in this calculation (see Sect. 7.2) using the isotopic validation data in Ref. 3, which consist of the values of the ratio of measured-tocalculated $(\mathrm{M} / \mathrm{C})$ fuel isotopic concentrations for the evaluated burnup credit isotopes. The random 
variable $X_{i}^{j}$, defined as shown in Eq. (2), is used to characterize the probability frequency distributions of the isotopic validation data.

$$
X_{i}^{j}=M_{i}^{j} / C_{i}^{j}
$$

where

$$
\begin{aligned}
i & =\text { the index of an isotope in the series of } 29 \text { burnup-credit isotopes, } \\
j & =\text { the index of a fuel sample in a series of } N_{S} \text { evaluated fuel samples, } \\
M_{i}^{j} & =\text { the measured concentration for the isotope } i \text { in the evaluated fuel sample } j, \\
C_{i}^{j} & =\text { the calculated concentration for the isotope } i \text { in the evaluated fuel sample } j .
\end{aligned}
$$

For large $N_{S}$, the $X_{i}^{j}$ values are expected to form a normal distribution with sample mean $\bar{X}_{i}$ and sample standard deviation $s_{i}$ given by Eqs. (3) and (4), respectively.

$$
\begin{gathered}
\bar{X}_{i}=\sum_{j=1}^{N_{S}} X_{i}^{j} / N_{S} . \\
S_{i}=\sqrt{\frac{\sum_{j=1}^{N_{S}}\left(X_{i}^{j}-\bar{X}_{i}\right)^{2}}{N_{S}-1}} .
\end{gathered}
$$

If the distribution parameters for a random variable were known exactly, the sample mean and standard deviation defined as shown in Eqs. (3) and (4) may be used to produce probability intervals. However, usually the distribution parameters are not known exactly, and tolerance intervals, rather than probability intervals, are used in statistical analyses. A tolerance interval is a statistical interval within which, with a specified certainty, a specified proportion $p$ of a population falls. Tolerance intervals are defined by lower $(L)$ and upper $(U)$ tolerance limits. The one-sided tolerance interval above the lower tolerance limit ensures that $p$ percentage of the population will not fall below the lower limit with a specified certainty, whereas the one-sided tolerance interval below the upper tolerance limit ensures that $p$ percentage of the population will not exceed the upper limit with a specified certainty. A two-sided tolerance interval is delimited by the lower and upper tolerance limits. For the ratio of measured-to-calculated isotopic concentration, the two-sided interval is defined by Eq. (5), whereas the one-sided tolerance intervals are given by Eqs. (6) and (7).

$$
\begin{gathered}
X_{i, L}=\bar{X}_{i}-k_{2} \cdot s_{i} ; \quad X_{i, U}=\bar{X}_{i}+k_{2} \cdot s_{i} . \\
X_{i, L}=\bar{X}_{i}-k_{1} \cdot s_{i} . \\
X_{i, U}=\bar{X}_{i}+k_{1} \cdot s_{i},
\end{gathered}
$$


where

$$
\begin{aligned}
& k_{2}=\text { two-sided tolerance-limit factor, } \\
& k_{1}=\text { one-sided tolerance-limit factor. }
\end{aligned}
$$

The $k_{1}$ and $k_{2}$ tolerance-limit factors depend on the type of the distribution, sample size, certainty, and percentage of the population. The values of the tolerance-limit factors used in this calculation were determined in the spreadsheet application available in $D V D / x l s /$ validation.xls, worksheet $t l$-factors, using the formulas provided in Appendix A.1.

\subsubsection{Application of the Monte Carlo Uncertainty Sampling Method}

A stochastic approach ${ }^{5}$ for estimating the total uncertainty in $k_{e f f}$ resulting from uncertainties in calculated isotopic compositions is based on Monte Carlo sampling of probability distributions obtained for the isotopic bias. This method simulates the variation of bias within the range of bias uncertainty by randomly sampling the uncertainty values. It involves a large number of criticality calculations using spent fuel compositions obtained by correcting the predicted spent fuel compositions for the sampled bias.

The characteristics of the probability distributions of isotopic validation data are greatly affected by the various characteristics of the evaluated RCA data, such as measurement and modeling uncertainties and sample size (refer to Sect. 7.2 for the characteristics of the isotopic validation data used in the current calculation). An improvement of the quality of the validation data may be obtained if additional RCA data characterized by low measurement uncertainties and detailed descriptions of sample irradiation environment become available. This will allow omitting some of the RCA data characterized by high measurement and/or modeling uncertainties from the isotopic validation data sets. With the availability of quality RCA data, the probability distributions of the isotopic validation data are expected to be approximately normal and the mean and standard deviation of the isotopic data are expected to be mostly determined by the uncertainty of the depletion calculation method.

In this calculation, the sampling distributions established for the $\mathrm{M} / \mathrm{C}$ isotopic concentration values are assumed to be normal with the expected mean and standard deviation given by Eqs. (3) and (4), respectively, and tolerance intervals (rather than confidence intervals) are used to define the range of bias uncertainty (see Sects. 6.3.1 and 7.2). The randomly sampled bias uncertainties for the burnupcredit isotopes in SNF compositions are applied to the predicted fuel concentrations as shown in Eq. (8) to determine new fuel isotopic concentrations for use in criticality calculations.

$$
c_{i}^{\prime j}=c_{i}^{j} \times\left(\bar{X}_{i}+r_{i}^{j} \cdot k_{2} \cdot s_{i}\right)
$$

where

\footnotetext{
$i=$ the index of an isotope in the series of the 29 burnup-credit isotopes,

$j=$ the index of a criticality calculation in a series of $N_{C}$ criticality calculations,

$c_{i}^{\prime j}=$ isotopic concentration corrected for bias and uncertainty in the predicted isotopic composition,

$c_{i}^{j}=$ predicted isotopic concentration,

$\bar{X}_{i}=$ the bias in the predicted fuel concentration for isotope $i$ [see Eqs. (2) and (3)],

$r_{i}^{j}=$ random number sampled from the standard normal distribution (i.e., the normal distribution with the distribution mean of zero and standard deviation of unity),
} 
$k_{2}=$ two-sided tolerance-limit factor for $95 \%$ certainty and $68.27 \%$ of the population,

$s_{i}=$ uncertainty associated with the bias in predicted fuel concentration for isotope $\mathrm{i}$ [see Eq. (4)].

The sample mean and standard deviation of the $k_{\text {eff }}$ values obtained using SNF compositions stochastically corrected for isotopic bias and uncertainty are determined as follows:

$$
\begin{gathered}
k_{e f f-M C}=\sum_{j=1}^{N_{C}} k_{e f f}^{j} / N_{C} . \\
\Delta k_{e f f-M C}=\sqrt{\frac{\sum_{j=1}^{N_{C}}\left(k_{e f f}^{j}-k_{e f f-M C}\right)^{2}}{N_{C}-1},},
\end{gathered}
$$

where

$$
\begin{aligned}
N_{C}= & \text { the number of criticality calculations, } \\
k_{e f f}^{j}= & \text { the } k_{\text {eff }} \text { value for criticality calculation } j \text { in a series of } N_{C} \text { criticality calculations, } \\
k_{\text {eff }-M C}= & \text { Monte Carlo estimate for } k_{\text {eff }} \text { showing the average effect on } k_{\text {eff }} \text { of isotopic } \\
& \text { composition correction for bias and bias uncertainty, } \\
\Delta k_{\text {eff }-M C}= & \text { uncertainty in the Monte Carlo estimate for } k_{\text {eff. }}
\end{aligned}
$$

The Monte Carlo uncertainty sampling method requires a statistically significant number of criticality calculations to ensure that the sampled bias uncertainty values are representative of the underlying distribution of the isotopic bias. Non-normal distributions usually require sophisticated methods for calculating tolerance-limit factors. Their values are greater than those of the tolerance-limit factors for normal distributions for the same sample size, certainty, and percentage of the population. Deviation from normality can be accounted for by using tolerance-limit factors for normal distributions that correspond to smaller sample sizes. The tolerance-limit factor increases with decreasing sample size and the increase is significant for small sample sizes $(<10)$.

\subsubsection{Calculation of the $\Delta k_{I S O}$ Term}

The change in reactivity due to isotopic composition bias and uncertainty in the calculated nuclide composition is determined according to Eq. (11), where $\Delta k_{\text {eff }-M C}$ is determined according to Eq. (10). The $\Delta k_{I S O}$ value is based on the upper tolerance limit for $95 \%$ of the population and $95 \%$ certainty.

$$
\Delta k_{\text {ISO }}=k_{\text {eff }-B E}-k_{\text {eff }}+k_{1} \times \Delta k_{e f f-M C}+2 u,
$$

where

$$
\begin{aligned}
k_{\text {eff }}= & \text { neutron multiplication factor value based on the depletion code predictions, } \\
k_{\text {eff }-B E}= & \text { neutron multiplication factor value based on the SNF composition corrected for isotopic } \\
& \text { bias (best-estimate value), }
\end{aligned}
$$


$k_{1}=1.84$, the value of the one-sided tolerance-limit factor for 200 statistical samples, $95 \%$ certainty, and $95 \%$ of the population (see spreadsheet $D V D / x l s /$ validation.xls),

$u=$ uncertainty resulting from the propagation of the uncertainties of the MCNP $k_{\text {eff }}$ values [see Eq. (12)].

The statistical uncertainty $u$ associated with the $\Delta k_{I S O}$ term is given by Eq. (12), which was obtained by propagating the statistical uncertainties of the MCNP $k_{\text {eff }}$ values to the uncertainty of the $k_{\text {eff }-M C}$ and $\Delta k_{I S O}$ terms in accordance with Eq. (13). Its value is approximately 0.0004 .

$$
u=\sigma \sqrt{2+\frac{k_{1}^{2}}{n-1}} \approx \sigma \sqrt{2}
$$

where $\sigma$ is the standard deviation of an MCNP $k_{\text {eff }}$ value (0.0003).

The uncertainty of a quantity $y$ that has a functional dependence on independent quantities $x_{i}, i=1, \ldots N$ may be determined by using Eq. (13) (Ref. 30).

$$
\sigma_{y}^{2}=\sum_{i=1}^{N}\left(\frac{\partial y}{\partial x_{i}}\right)^{2} \sigma_{x_{i}}^{2}
$$

where $\sigma_{x_{i}}$ is the standard uncertainty associated with the estimate $x_{i}$. The derivation of the uncertainty $u$ was simplified based on the approximation shown in Eq. (14) so that the dependence between $k_{\text {eff-MC }}$ and each $k_{\text {eff }}^{i}$ could be removed:

$$
k_{e f f-M C}=\sum_{i=1}^{N_{C}} k_{e f f}^{i} / N_{C} \approx\left(k_{e f f}^{1}+k_{e f f}^{2}+\cdots+k_{e f f}^{i-1}+k_{e f f}^{i+1}+\cdots+k_{e f f}^{N_{c}}\right) /\left(N_{c}-1\right) .
$$

This approximation is valid for converged $k_{e f f-M C}$ values since omitting a single $k_{\text {eff }}$ value from the series of $N_{c} k_{e f f}$ values has insignificant impact on the average value if the series is converged.

\subsection{BOUNDING METHOD}

The bounding method uses isotopic composition bias and bias uncertainty values in a way that maximizes the $k_{\text {eff }}$ value. Specifically, the predicted concentration of a fissile $\left({ }^{235} \mathrm{U},{ }^{239} \mathrm{Pu}\right.$, and $\left.{ }^{241} \mathrm{Pu}\right)$ isotope is replaced by its upper tolerance limit [see Eq. (7)], whereas the predicted concentration of a neutron absorbing isotope is replaced by its lower tolerance limit [see Eq. (6)] for one-sided tolerance intervals, as shown in Eq. (15). The tolerance-limit factor in Eq. (15) is a function of the number of evaluated fuel samples for the burnup-credit isotope and corresponds to specified certainty and percentage of the population ( $95 / 95$ in this calculation).

$$
c_{i}^{\prime}=\left\{\begin{array}{l}
c_{i} \times\left(\bar{X}_{i}+k_{1} \cdot s_{i}\right), \text { for fissile isotopes } \\
c_{i} \times\left(\bar{X}_{i}-k_{1} \cdot s_{i}\right), \text { for neutron absorbing isotopes }
\end{array},\right.
$$


where

$$
\begin{aligned}
i= & \text { the index of an isotope in the series of the } 29 \text { burnup-credit isotopes, } \\
c_{i}^{\prime}= & \text { isotopic concentration adjusted for bias and bias uncertainty to maximize positive } \\
& \text { reactivity } \\
c_{i}= & \text { predicted isotopic concentration, } \\
\bar{X}_{i}= & \text { the bias in the predicted fuel concentration for isotope } i \text { [see Eq. (3)], } \\
k_{1}= & \text { one-sided tolerance-limit factor, } \\
s_{i}= & \text { uncertainty associated with the bias in predicted fuel concentration for isotope } i \\
& \text { [see Eq. (4)]. }
\end{aligned}
$$

The bounding method requires a criticality calculation using adjusted SNF isotopic concentrations as shown in Eq. (15) and another criticality calculation using predicted SNF compositions. However, this method maximizes the effects of isotopic composition uncertainties on system reactivity in a nonphysical way when it is coupled with the use of conservative depletion parameters that maximize the spent fuel residual reactivity. Application of the bounding method can be justified if confidence in the RCA data available for validation is limited (i.e., in the case of large measurement uncertainties and inadequate availability of modeling data, if the range of parameters characteristic to the evaluated RCA data has limited applicability), or detailed assembly-specific operating history parameters are used in the depletion calculations. 


\section{CALCULATIONS}

\subsection{CALCULATION OF BOUNDING ISOTOPIC COMPOSITIONS FOR PWR WASTE PACKAGES}

Considerable variation in design and irradiation history parameters exists among SNF assemblies. This section describes the assembly design and irradiation parameters established to be conservative with respect to waste package criticality (i.e., to increase residual reactivity at fuel discharge) and used in the development of loading curves for commercial SNF disposal. ${ }^{18}$ Those modeling parameters were used in depletion calculations to determine bounding isotopic compositions for criticality calculations.

\subsubsection{Bounding Assembly Parameters for Depletion Calculations}

The PWR assembly type selected for depletion and criticality calculations is the Babcock and Wilcox $(\mathrm{B} \& \mathrm{~W}) 15 \times 15$ assembly. The basis for this selection is that the $\mathrm{B} \& \mathrm{~W} 15 \times 15$ assembly is one of the most reactive assembly designs in a waste package configuration, as established in a sensitivity study documented in Ref. 31, Attachment II. The sensitivity study compared the B\&W $15 \times 15$ fuel assemblies with Westinghouse $(15 \times 15$ and $17 \times 17$, OFA and STD) and Combustion Engineering $(14 \times 14,15$ $\times 15$, and $16 \times 16$ ) assembly types using fresh fuel of $5 \mathrm{wt} \%{ }^{235} \mathrm{U}$ enrichment. The MCNP $k_{\text {eff }}$ values obtained for the $\mathrm{B} \& \mathrm{~W} 15 \times 15$ and Westinghouse $17 \times 17$ OFA were statistically identical. Additional information supporting the selection of the $\mathrm{B} \& \mathrm{~W} 15 \times 15$ design is provided in Ref. 15.

Fuel pin, guide tube, and instrument tube locations in the B\&W $15 \times 15$ assembly are illustrated in Fig. 1; fuel assembly design parameters are presented in Table 3; selected assembly initial enrichment and burnup values for the PWR isotopic-composition database are shown in Table 4; material compositions for cladding and burnable poison rod (BPR) materials are presented in Table 5; and additional modeling parameters that are conservative with respect to waste package reactivity are presented in Table 6.

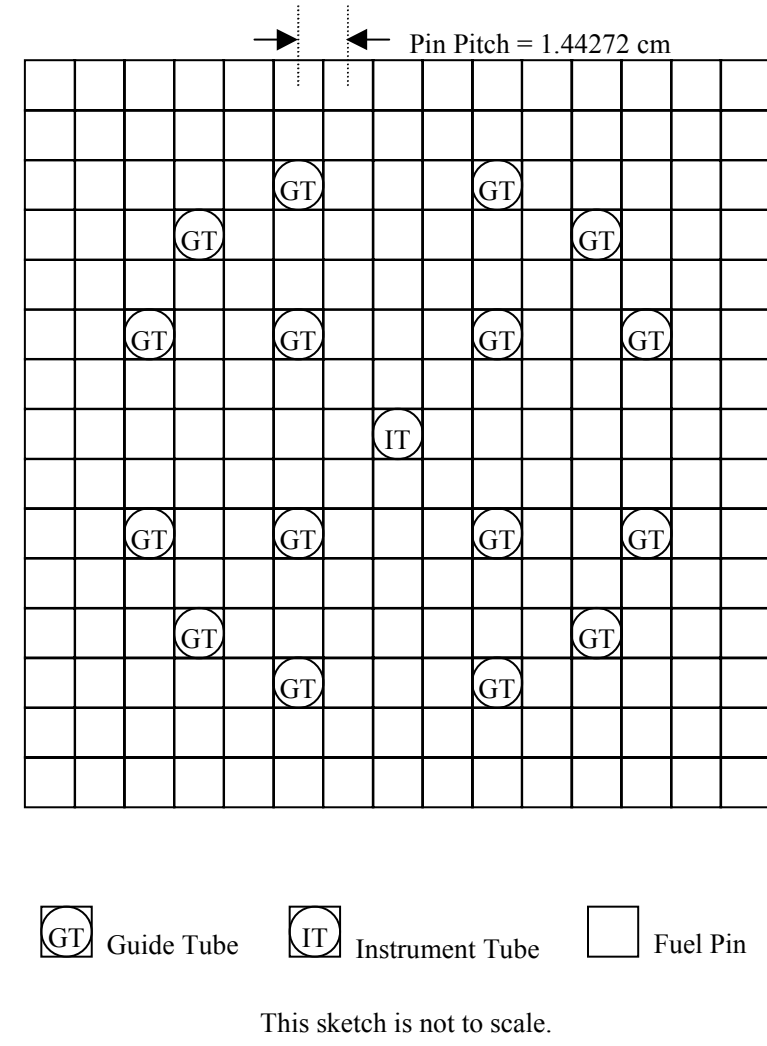

Fig. 1. Fuel pin, guide tube, and instrument tube locations in the B\&W $15 \times 15$ PWR fuel assembly. 
Table 3. PWR fuel assembly specifications for isotopic composition calculations

\begin{tabular}{|c|c|}
\hline Design parameter & Parameter value \\
\hline Lattice & $15 \times 15$ \\
\hline Active fuel length & $357.111 \mathrm{~cm}$ \\
\hline Assembly pitch & 21.811 \\
\hline Pin pitch & $1.44272 \mathrm{~cm}$ \\
\hline Fuel pellet outer diameter & $0.9398 \mathrm{~cm}$ \\
\hline Fuel rod cladding inner diameter & $0.95758 \mathrm{~cm}$ \\
\hline Fuel rod cladding outer diameter & $1.0922 \mathrm{~cm}$ \\
\hline Burnable poison rod (BPR) outer diameter & 0.8636 \\
\hline BPR clad inner diameter & 0.9144 \\
\hline BPR clad outer diameter & 1.0922 \\
\hline Guide tube inner diameter & $1.2649 \mathrm{~cm}$ \\
\hline Guide tube outer diameter & $1.3462 \mathrm{~cm}$ \\
\hline Instrument tube inner diameter ${ }^{a}$ & $1.12014 \mathrm{~cm}$ \\
\hline Instrument tube outer diameter ${ }^{a}$ & $1.38193 \mathrm{~cm}$ \\
\hline Number of fuel cells in fuel assembly & 208 \\
\hline Number of BPR cells in fuel assembly & 16 \\
\hline Fuel density $^{b}$ & $10.741 \mathrm{~g} / \mathrm{cm}^{3}$ \\
\hline Fuel initial enrichment and burnup values & See Table 4 \\
\hline Fuel clad, guide tube, and instrument tube material & Zircaloy-4 (See ) \\
\hline BPR material composition & $3.5 \mathrm{wt} \% \mathrm{~B}_{4} \mathrm{C}$ in $\mathrm{Al}_{2} \mathrm{O}_{3}$ (See ) \\
\hline
\end{tabular}

Source: Ref. 15 unless otherwise noted.

${ }^{a}$ Ref. 16.

${ }^{b}$ Calculated based on $98 \%$ theoretical density value of $10.96 \mathrm{~g} / \mathrm{cm}^{3}$ for $\mathrm{UO}_{2}$.

Table 4. Selected enrichment and burnup values for the PWR SNF isotopic database

\begin{tabular}{|c|c|}
\hline Enrichment $\mathbf{(}^{235} \mathbf{U}$ wt $\left.\%\right)$ & Burnup (GWd/MTU) \\
\hline 1.5 & $0.001,2.5,5,7.5,10,12.5,15,17.5,20,25,30,35,40,45,50,60,65,70,75$ \\
\hline 2.0 & $0.001,2.5,5,7.5,10,12.5,15,17.5,20,25,30,35,40,45,50,60,65,70,75$ \\
\hline 2.5 & $0.001,2.5,5,7.5,10,12.5,15,17.5,20,25,30,35,40,45,50,60,65,70,75$ \\
\hline 3.0 & $0.001,2.5,5,7.5,10,12.5,15,17.5,20,25,30,35,40,45,50,60,65,70,75$ \\
\hline 3.5 & $0.001,2.5,5,7.5,10,12.5,15,17.5,20,25,30,35,40,45,50,60,65,70,75$ \\
\hline 4.0 & $0.001,2.5,5,7.5,10,12.5,15,17.5,20,25,30,35,40,45,50,60,65,70,75$ \\
\hline 4.5 & $0.001,2.5,5,7.5,10,12.5,15,17.5,20,25,30,35,40,45,50,60,65,70,75$ \\
\hline 5.0 & $0.001,2.5,5,7.5,10,12.5,15,17.5,20,25,30,35,40,45,50,60,65,70,75$ \\
\hline 5.5 & $0.001,2.5,5,7.5,10,12.5,15,17.5,20,25,30,35,40,45,50,60,65,70,75$ \\
\hline
\end{tabular}


Table 5. Chemical compositions and mass densities for Zircaloy-4 and burnable poison

\begin{tabular}{|l|l|l|l|}
\hline \multicolumn{2}{|c|}{ Zircaloy-4 } & \multicolumn{2}{c|}{ Burnable poison } \\
\hline \multicolumn{1}{|c|}{ Element } & wt \% & Element/isotope & wt \% \\
\hline $\mathrm{O}$ & 0.125 & ${ }^{10} \mathrm{~B}$ & 0.5023 \\
\hline $\mathrm{Cr}$ & 0.100 & ${ }^{11}$ Boron & 2.2370 \\
\hline $\mathrm{Fe}$ & 0.210 & $\mathrm{C}$ & 0.7608 \\
\hline $\mathrm{Zr}$ & 98.115 & $\mathrm{Al}$ & 51.0727 \\
\hline $\mathrm{Sn}$ & 1.450 & $\mathrm{O}$ & 45.4273 \\
\hline Density $=6.56 \mathrm{~g} / \mathrm{cm}^{3}$ & & Density $=3.7 \mathrm{~g} / \mathrm{cm}^{3}$ & \\
\hline
\end{tabular}

Source: Ref. 15.

Table 6. Additional bounding modeling parameters

\begin{tabular}{|l|l|l|}
\hline \multicolumn{1}{|c|}{$\begin{array}{c}\text { Modeling } \\
\text { parameter }\end{array}$} & Parameter value & \multicolumn{1}{c|}{ Justification/comments $^{a}$} \\
\hline Fuel temperature & $1144.1 \mathrm{~K}$ & $\begin{array}{l}\text { The value was based on operating parameters for PWRs. A } \\
\text { higher fuel temperature value results in more }{ }^{239} \text { Pu production. }\end{array}$ \\
\hline $\begin{array}{l}\text { Moderator } \\
\text { temperature }\end{array}$ & $588.7 \mathrm{~K}$ & $\begin{array}{l}\text { The value was based on operating parameters for PWRs. The } \\
\text { bounding temperature is approximately 20 degrees above the } \\
\text { core average value. }\end{array}$ \\
\hline Moderator density & $0.6905 \mathrm{~g} / \mathrm{cm}^{3}$ & $\begin{array}{l}\text { Moderator density value was taken from steam tables and } \\
\text { corresponds to the moderator temperature and pressure. }\end{array}$ \\
\hline $\begin{array}{l}\text { Soluble boron in } \\
\text { moderator }\end{array}$ & $1000 \mathrm{ppmB}$ & $\begin{array}{l}\text { Soluble boron value is constant throughout the irradiation time } \\
\text { period. The value was based on operating parameters for the } \\
\text { PWR Crystal River Unit 3. A larger soluble boron concentration } \\
\text { results in more }{ }^{239} \text { Pu production. }\end{array}$ \\
\hline BPR insertion & Maximum (16) & $\begin{array}{l}\text { BPR insertion in every guide tube location throughout the } \\
\text { irradiation time period maximizes the fissile isotope (primarily } \\
\text { 235 U and }{ }^{239} \text { Pu) content }\end{array}$ \\
\hline Specific power & $29.74 \mathrm{MW} / \mathrm{MTU}$ & $\begin{array}{l}\text { Specific power has a weak effect upon reactivity. Lower } \\
\text { specific power values result in greater fuel reactivity. }\end{array}$ \\
\hline $\begin{array}{l}\text { Depletion time step } \\
\text { interval }\end{array}$ & 50 days & $\begin{array}{l}\text { Provides adequate cross-section update frequency for BPR } \\
\text { depletion calculations. }\end{array}$ \\
\hline
\end{tabular}

Source: Ref. 15.

${ }^{a}$ Parameter values are bounding with respect to criticality, as justified in Ref. 15 . 


\subsubsection{TRITON/NEWT Modeling}

TRITON/NEWT calculations were performed for all enrichment-burnup pair values listed in Table 4 to generate a PWR spent fuel composition database based on the assembly bounding parameters illustrated in Fig. 1 and tabulated in Table 3 and Table 6. Additional input data, such as minor actinide concentrations in fresh fuel and the time for the last depletion step, were taken directly from the similar depletion calculations using SAS2H documented in Ref. 15. One quarter of the B\&W $15 \times 15$ assembly with reflective boundary conditions, as shown in Fig. 2, was modeled for TRITON/NEWT depletion calculations. The burnable poison ${ }^{10} \mathrm{~B}$ was depleted throughout the entire irradiation time period. The burnable poison typically burns out after the first cycle, but the BPR was left inserted for its moderator displacement effects, which result in a harder spectrum and thus a higher residual reactivity at fuel discharge.

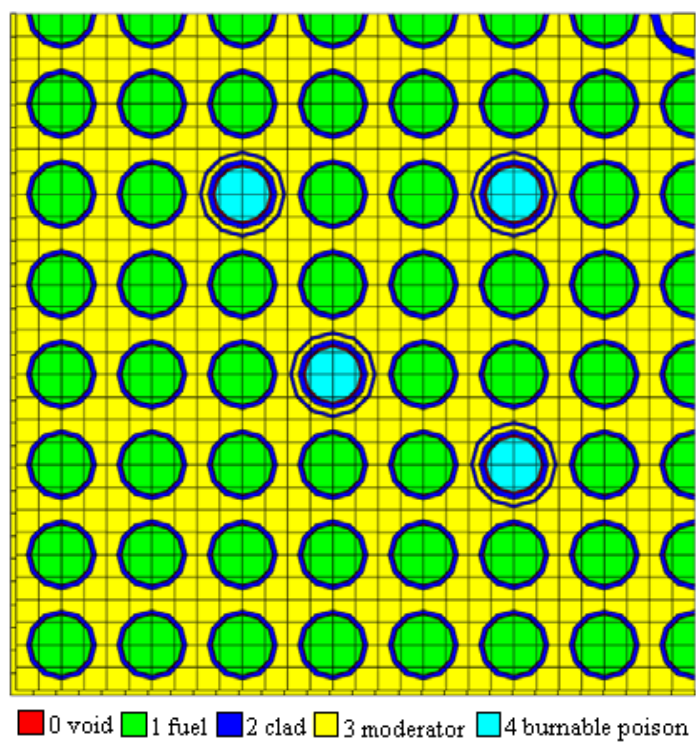

Fig. 2. TRITON/NEWT geometry representation of the B\&W $15 \times 15$ assembly with BPRs fully inserted.

\subsection{CHARACTERIZATION OF SCALE 5.1 ISOTOPIC VALIDATION DATA}

Reference 3 provides a comprehensive evaluation of available PWR RCA data for use in depletion code validations and the comparison to measurement of the SCALE 5.1 isotopic concentration predictions. The evaluated RCA data comprise measured isotopic concentrations for 118 fuel samples obtained from low-, moderate-, and high-burnup fuel assemblies irradiated in the following nine PWRs: Trino Vercellese, Kernkraftwerk Obrigheim, Turkey Point Unit 3, H. B. Robinson Unit 2, Calvert Cliffs Unit 1, Three Mile Island (TMI) Unit 1, Takahama Unit 3, Gösgen, and GKN II. The initial enrichment and burnup of the evaluated fuel samples vary from 2.453 to $4.657 \mathrm{wt} \%{ }^{235} \mathrm{U}$ and from 7.2 to $70.4 \mathrm{GWd} / \mathrm{MTU}$, respectively. For illustrative purposes, a comparison of the enrichment and burnup values of the evaluated fuel samples to the actual and projected spent fuel assembly inventory and typical loading curve for PWR SNF assuming actinide and fission product burnup credit is shown in Fig. 3 (Ref. 3). Relevant parameters of the evaluated fuel samples are summarized in Table 7. For each individual RCA data set, the table presents the name of the reactor in which the measured fuel samples were irradiated, the name of the experimental program, fuel assembly design and initial enrichment, the range of the burnup for the evaluated fuel samples, the number of measured samples/rods, and the number of burnup credit isotopes evaluated. The number of the isotopes with measured concentrations varies depending on the experimental program. The earlier experimental programs generally provided measurement data for the uranium and plutonium isotopes, whereas the more recent experimental programs provided measurement data for up to 50 isotopes, including actinide and fission product isotopes relevant to burnup credit. The computer code and the cross-section library used in Ref. 3 to perform depletion calculations for the 118 evaluated fuel samples is the two-dimensional transport and depletion module, TRITON/NEWT, and the 44GROUPNDF5 cross-section library, respectively, in the SCALE 5.1 code system. ${ }^{3}$ 


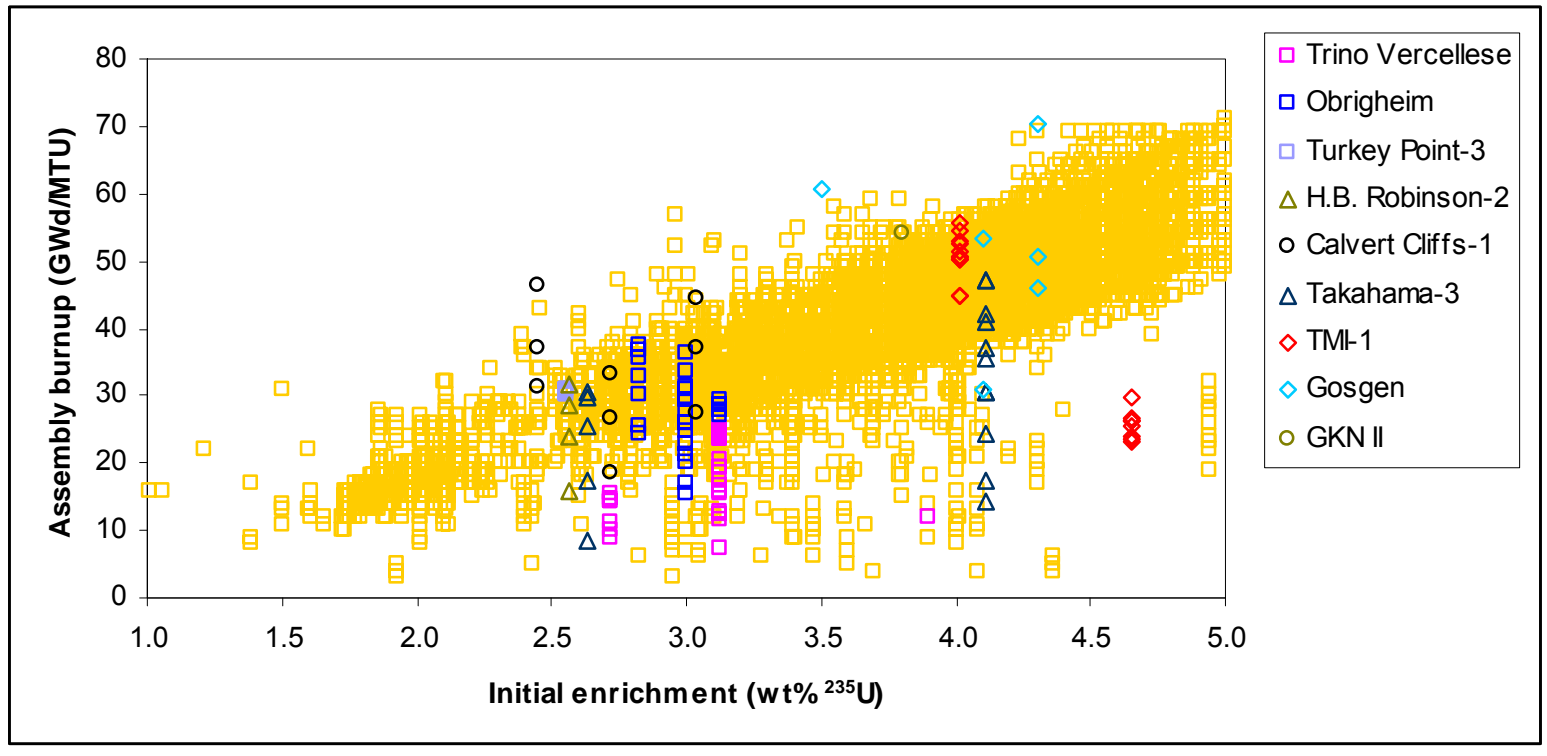

Fig. 3. Enrichment and burnup values of the evaluated spent fuel samples compared to the actual and projected spent fuel assembly inventory and typical loading curve for PWR SNF assuming actinide and fission product burnup credit. (Note: Each point for the existing inventory represents multiple assemblies.) 
Table 7. Relevant parameters of the evaluated RCA data

\begin{tabular}{|c|c|c|c|c|c|c|}
\hline Reactor & $\begin{array}{c}\text { Experimental } \\
\text { program } \\
\text { name }\end{array}$ & $\begin{array}{c}\text { Assembly } \\
\text { design }\end{array}$ & $\begin{array}{c}\text { Initial } \\
\text { enrichment } \\
\text { (wt } \%{ }^{235} U \text { ) }\end{array}$ & $\begin{array}{l}\text { No. of } \\
\text { samples/ } \\
\text { fuel rods }\end{array}$ & $\begin{array}{c}\text { Burnup } \\
\text { (GWd/MTU) }\end{array}$ & $\begin{array}{c}\text { No. of } \\
\text { measured } \\
\text { burnup credit } \\
\text { isotope }^{a}\end{array}$ \\
\hline Trino & EURATOM & $15 \times 15$ & $\begin{array}{l}2.719,3.13, \\
3.897\end{array}$ & $15 / 5$ & $7.2-17.5$ & 8 \\
\hline Vercellese & EURATOM & $15 \times 15$ & 3.13 & $16 / 5$ & $12.8-25.3$ & 10 \\
\hline \multirow[t]{2}{*}{ Obrigheim } & EURATOM & $14 \times 14$ & $2.83,3.00$ & $22 / 6$ & $15.6-37.5$ & 8 \\
\hline & $\mathrm{ICE}^{b}$ & $14 \times 14$ & 3.13 & $5 / 5$ & $27.0-29.4$ & 8 \\
\hline Turkey Point-3 & C-SFT ${ }^{c}$ & $15 \times 15$ & 2.556 & $5 / 2$ & $30.5-31.6$ & 9 \\
\hline H. B. Robinson-2 & $\mathrm{ATM}-101^{d}$ & $15 \times 15^{e}$ & 2.561 & $4 / 1$ & $16.0-31.7$ & 13 \\
\hline \multirow[t]{3}{*}{ Calvert Cliffs- 1} & ATM-104 & $14 \times 14$ & 3.038 & $3 / 1$ & $27.4-44.3$ & 20 \\
\hline & ATM-103 & $14 \times 14$ & 2.72 & $3 / 1$ & $18.7-33.2$ & 12 \\
\hline & ATM-106 & $14 \times 14$ & 2.453 & $3 / 1$ & $31.4-46.5$ & 21 \\
\hline Takahama-3 & JAERI $^{f}$ & $17 \times 17^{g}$ & $2.63,4.11$ & $16 / 3$ & $7.8-47.3$ & 20 \\
\hline \multirow[t]{2}{*}{ TMI-1 } & DOE YMP ${ }^{h}$ & $15 \times 15^{e}$ & 4.013 & $11 / 1$ & $44.8-55.7$ & 28 \\
\hline & DOE YMP & $15 \times 15^{e, g}$ & 4.657 & $8 / 3$ & $22.8-29.9$ & 23 \\
\hline \multirow[t]{2}{*}{ Gösgen } & ARIANE $^{i}$ & $15 \times 15$ & $3.5,4.1$ & $3 / 2$ & $29.1-59.7$ & 28 \\
\hline & MALIBU $^{i}$ & $15 \times 15$ & 4.3 & $3 / 1$ & $47.2-70.4$ & 28 \\
\hline GKN II & REBUS $^{i}$ & $18 \times 18$ & 3.8 & $1 / 1$ & 54.1 & 27 \\
\hline
\end{tabular}

Source: Ref. 3.

${ }^{a}$ Maximum number of burnup credit isotopes in a sample measured/evaluated for each experimental program. The evaluated isotopes are tabulated in the tables included in Sect. 10.1 of Ref. 3. Note that measurement data for ${ }^{233} \mathrm{U}$ is not available because ${ }^{233} \mathrm{U}$ concentrations in the current commercial SNF are negligible.

${ }^{b}$ Isotopic Correlation Experiment.

${ }^{c}$ CLIMAX - Spent Fuel Test.

${ }^{d}$ Approved Testing Material.

${ }^{e}$ Assembly with burnable poison rods.

${ }_{\text {J Japan Atomic Energy Research Institute (now Japan Atomic Energy Agency) }}$

${ }^{g}$ Assembly with $\mathrm{Gd}_{2} \mathrm{O}_{3}$ rods.

${ }^{h}$ U.S. Department of Energy Yucca Mountain Project.

${ }^{i}$ International Experimental Programs coordinated by Belgonucleaire, Belgium - currently managed by Studiecentrum voor Kernenergie - Centre d'étude de l'Energie Nucléaire (SCK·CEN) Laboratory (Ref. 32).

The measured-to-calculated (M/C) isotopic concentration values provided in Ref. 3, Tables 97 through 106, for the measured isotopes in the 118 PWR fuel samples comprise the isotopic validation data for disposal criticality analysis of PWR waste packages and are used in this calculation to determine the penalty in waste package reactivity due to isotopic composition bias and uncertainty in calculated SNF isotopic compositions. The characteristics of the frequency distributions of the validation data, including sample mean and standard deviation [see Eqs. (3) and (4), respectively], the results of a normality test, and the results of hypothesis testing for identifying statistically significant trending of the $\mathrm{M} / \mathrm{C}$ isotopic concentration values with sample burnup are presented in Table 8 . The $\mathrm{M} / \mathrm{C}$ isotopic concentration values are not correlated with sample initial enrichment (see spreadsheet DVD/xls/isotopics_for_criticality.xls, worksheet MoC stats). 
Table 8. Characteristics of the frequency distributions of the $M / C$ isotopic concentration values

\begin{tabular}{|c|c|c|c|c|c|c|c|}
\hline Isotope & $\bar{X}_{i}^{a}$ & $s_{i}{ }^{a}$ & $\begin{array}{c}\text { No. of } \\
\text { samples }\end{array}$ & $\begin{array}{c}\text { Enrichment } \\
\text { range } \\
\text { (wt } \%{ }^{235} U \text { ) }\end{array}$ & $\begin{array}{c}\text { Burnup } \\
\text { range } \\
\text { (GWd/MTU) }\end{array}$ & $\begin{array}{c}\text { Normal } \\
\text { distribution }^{b}\end{array}$ & $\begin{array}{l}\text { Correlation with } \\
\text { burnup }^{c}\end{array}$ \\
\hline${ }^{234} \mathrm{U}$ & 0.9348 & 0.1254 & 70 & $2.453-4.657$ & $7.2-70.4$ & No & No \\
\hline${ }^{235} \mathrm{U}$ & 0.9934 & 0.0517 & 118 & $2.453-4.657$ & $7.2-70.4$ & No & No \\
\hline${ }^{236} \mathrm{U}$ & 1.0069 & 0.0373 & 118 & $2.453-4.657$ & $7.2-70.4$ & Yes & Yes \\
\hline${ }^{238} \mathrm{U}$ & 1.0014 & 0.0035 & 118 & $2.453-4.657$ & $7.2-70.4$ & No & Yes \\
\hline${ }^{237} \mathrm{~Np}$ & 0.9485 & 0.1340 & 49 & $2.453-4.657$ & $8.6-70.4$ & No & No \\
\hline${ }^{238} \mathrm{Pu}$ & 1.0758 & 0.1091 & 103 & $2.453-4.657$ & $8.6-70.4$ & No & No \\
\hline${ }^{239} \mathrm{Pu}$ & 0.9526 & 0.0528 & 118 & $2.453-4.657$ & $7.2-70.4$ & No & Yes \\
\hline${ }^{240} \mathrm{Pu}$ & 0.9668 & 0.0488 & 118 & $2.453-4.657$ & $7.2-70.4$ & No & Yes \\
\hline${ }^{241} \mathrm{Pu}$ & 1.0065 & 0.0643 & 118 & $2.453-4.657$ & $7.2-70.4$ & No & No \\
\hline${ }^{242} \mathrm{Pu}$ & 1.0071 & 0.0763 & 117 & $2.453-4.657$ & $7.2-70.4$ & No & No \\
\hline${ }^{241} \mathrm{Am}$ & 0.9795 & 0.2143 & 59 & $2.453-4.657$ & $8.6-70.4$ & Yes & No \\
\hline${ }^{242 \mathrm{~m}} \mathrm{Am}$ & 0.9320 & 0.2173 & 44 & $2.63-4.657$ & $8.6-70.4$ & Yes & Yes \\
\hline${ }^{243} \mathrm{Am}$ & 0.8745 & 0.1654 & 52 & $2.63-4.657$ & $8.6-70.4$ & No & No \\
\hline${ }^{95} \mathrm{Mo}$ & 0.9935 & 0.0610 & 18 & $3.5-4.3$ & $31.1-70.4$ & Yes & No \\
\hline${ }^{99} \mathrm{Tc}$ & 0.9203 & 0.1306 & 31 & $2.453-4.3$ & $16.0-70.4$ & No & No \\
\hline${ }^{101} \mathrm{Ru}$ & 0.9452 & 0.0798 & 18 & $3.5-4.3$ & $31.1-70.4$ & Yes & No \\
\hline${ }^{103} \mathrm{Rh}$ & 0.9240 & 0.1084 & 19 & $2.453-4.3$ & $31.1-70.4$ & No & No \\
\hline${ }^{109} \mathrm{Ag}$ & 0.5507 & 0.2009 & 17 & $3.5-4.3$ & $44.8-70.4$ & No & No \\
\hline${ }^{143} \mathrm{Nd}$ & 0.9742 & 0.0439 & 50 & $2.453-4.657$ & $8.6-70.4$ & No & Yes \\
\hline${ }^{145} \mathrm{Nd}$ & 0.9812 & 0.0275 & 50 & $2.453-4.657$ & $8.6-70.4$ & No & No \\
\hline${ }^{147} \mathrm{Sm}$ & 0.9890 & 0.0759 & 36 & $2.453-4.657$ & $17.4-70.4$ & No & No \\
\hline${ }^{149} \mathrm{Sm}$ & 0.8885 & 0.0694 & 32 & $3.5-4.657$ & $17.4-70.4$ & Yes & No \\
\hline${ }^{150} \mathrm{Sm}$ & 0.9442 & 0.0534 & 36 & $2.453-4.657$ & $17.4-70.4$ & No & No \\
\hline${ }^{151} \mathrm{Sm}$ & 0.7486 & 0.0560 & 36 & $2.453-4.657$ & $17.4-70.4$ & Yes & No \\
\hline${ }^{152} \mathrm{Sm}$ & 0.7888 & 0.0612 & 36 & $2.453-4.657$ & $17.4-70.4$ & Yes & Yes \\
\hline${ }^{151} \mathrm{Eu}$ & 1.0688 & 0.3831 & 23 & $3.5-4.657$ & $23.7-70.4$ & No & No \\
\hline${ }^{153} \mathrm{Eu}$ & 0.9735 & 0.0727 & 30 & $2.453-4.657$ & $23.7-70.4$ & No & Yes \\
\hline${ }^{155} \mathrm{Gd}$ & 1.7161 & 0.3452 & 30 & $2.453-4.657$ & $23.7-70.4$ & No & No \\
\hline
\end{tabular}

Source: Ref. 3.

${ }^{a}$ Sample mean $\left(\bar{X}_{i}\right)$ and standard deviation $\left(s_{i}\right)$ of the M/C isotopic concentration values derived in DVD/xls/isotopics_for_criticality.xls, worksheet bias (see Appendix C). The $\mathrm{M} / \mathrm{C}$ isotopic concentration values in file isotopics_for_criticality.xls were obtained from Ref. 3, Appendix B.1, DVD/xls.zip/all_results.xls.

${ }^{b}$ The results of Shapiro-Wilk normality test at the 0.05 significance level performed using Origin are available in DVD/opj/bias.opj (see Appendix C).

${ }^{c}$ Statistical significance of trending with burnup was determined in spreadsheet $D V D / x l s /$ isotopics_for_criticality.xls, worksheet MoC stats (see Appendix C) using the hypothesis test for slope of regression line described in Appendix A.2 and the upper critical values of Student's distribution corresponding to a significance level of 0.05 , which are provided in Ref. 20, Sect. 1.3.6.7.2. 
Many classical statistical methods, including the Monte Carlo uncertainty sampling method described in Sect. 6.3, rely on the assumption of normality of data to make probabilistic inferences from samples to populations. As indicated in Table 8, the $\mathrm{M} / \mathrm{C}$ isotopic concentration values obtained for the majority of the burnup-credit isotopes do not approach the normal distribution. However, the frequency distributions of the $\mathrm{M} / \mathrm{C}$ isotopic concentration values appear to be unimodal and symmetrical about a central value with varying degrees of kurtosis (see the histogram plots for the frequency distributions of the $\mathrm{M} / \mathrm{C}$ isotopic concentration values for each burnup-credit isotope in DVD/opj/bias.opj). Positive kurtosis indicates that a larger fraction of the $\mathrm{M} / \mathrm{C}$ isotopic concentration values are concentrated symmetrically about a central value than that observed in the case of the normal distribution. The frequency distributions of the $\mathrm{M} / \mathrm{C}$ isotopic concentration values for fission products with a small number of evaluated samples, such as ${ }^{109} \mathrm{Ag}$ and ${ }^{151} \mathrm{Eu}$, appear to be unimodal and skewed. As shown in Table 9, the frequencies with which the $\mathrm{M} / \mathrm{C}$ isotopic concentration values fall within $\pm 1, \pm 2$, and \pm 3 standard deviations of the distribution's mean vary from 60 to $88 \%$, from 92 to $100 \%$, and from 95 to $100 \%$, respectively. For the normal distribution of mean $\mu$ and standard deviation $\sigma, 68.27 \%$ of the population fall between $\mu \pm 1 \sigma, 95.45 \%$ of the population falls between $\mu \pm 2 \sigma$, and $99.73 \%$ of the population fall between $\mu \pm 3 \sigma$ (Ref. 20, Sect. 6.5.1).

Statistical hypothesis testing (see Appendix A.2) was used to determine whether an observed correlation between the $\mathrm{M} / \mathrm{C}$ isotopic concentration and burnup values had occurred by chance or was statistically significant. Linear relationships between the $\mathrm{M} / \mathrm{C}$ isotopic concentration and burnup values were determined for the eight isotopes identified in Table 8 . By removing the $\mathrm{M} / \mathrm{C}$ isotopic concentration values obtained for the TMI-1 assembly NJ05YU, a dependence on burnup was indicated by the hypothesis test only for the ${ }^{238} \mathrm{U}$ and ${ }^{240} \mathrm{Pu}$ isotopes. As indicated in Ref. 3, the TMI-1 assembly NJ05YU was burnt to approximately $50 \mathrm{GWd} / \mathrm{MTU}$ in atypical irradiation conditions and the $\mathrm{M} / \mathrm{C}$ isotopic concentration values obtained for the TMI samples are likely affected by large experimental and modeling uncertainties; therefore, the isotopic validation results for this assembly also appear to be atypical. The $\mathrm{M} / \mathrm{C}$ isotopic concentration values for the other measured fuel samples with burnup greater than $45 \mathrm{GWd}$ /MTU (i.e., Gösgen, Takahama, Calvert Cliffs, and GKN samples) are well within the range of the $\mathrm{M} / \mathrm{C}$ isotopic concentration values obtained for the lower-burnup fuel samples. Therefore, a real variation of the $\mathrm{M} / \mathrm{C}$ isotopic concentration values with burnup appears to be unlikely; rather, the $\mathrm{M} / \mathrm{C}$ isotopic concentration values for the samples from the TMI-1 assembly NJ05YU are likely affected by measurement and/or computational modeling bias. No correlation between the $\mathrm{M} / \mathrm{C}$ isotopic concentration values and sample initial enrichment was identified for any of the burnup-credit isotopes.

Bias and uncertainty associated with measurement and calculation modeling, as well as the bias and uncertainty associated with the depletion code, are intrinsic components of isotopic validation data. The reported measurement uncertainties vary considerably, depending on the experimental program. For instance, the measurement uncertainties for the uranium and plutonium isotopes in the Takahama fuel samples and in the TMI-1 fuel samples (from assembly NJ05YU) measured at Argonne National Laboratory vary from 0.1 to $2 \%$ and from 3.7 to $7.9 \%$, respectively. ${ }^{3}$ Sources of potential modeling uncertainties have been identified for some of the evaluated fuel samples (e.g., the measured samples in the Obrigheim assemblies BE124 and BE210) (Ref. 3). However, a quantification of the potential effects that modeling uncertainties may have on the isotopic bias and bias uncertainty is not possible since the required data for more detailed modeling is not available for some of the evaluated fuel samples. The variations in the magnitude of measurement and modeling uncertainties across the evaluated fuel samples affect the calculated $\mathrm{M} / \mathrm{C}$ isotopic concentration values in a nonuniform manner, thus producing anomalies in the frequency distributions of the isotopic validation data. The intent of this brief analysis was only to emphasize the complexity of the isotopic validation data. No attempt was made to remove atypical data from the isotopic validation data set. 


\subsubsection{Area of Applicability}

The initial enrichment and burnup for the spent fuel in the application model range from 2.5 to $5 \mathrm{wt} \%{ }^{235} \mathrm{U}$ and from 5 to $45 \mathrm{GWd} / \mathrm{MTU}$, respectively. ${ }^{18}$ The ranges of initial enrichment and burnup for each burnup-credit isotope in the evaluated spent fuel samples vary depending on the isotope, as shown in Table 8. In this calculation, the range of applicability of the isotopic composition validation data is expanded upward to higher initial enrichment values and downward to lower burnup values. The enrichment applicability was extended from either 4.657 or $4.3 \mathrm{wt} \%{ }^{235} \mathrm{U}$ to $5 \mathrm{wt} \%{ }^{235} \mathrm{U}$. The burnup applicability was slightly expanded downward for actinide isotopes from either 7.2 or 8.6 $\mathrm{GWd} / \mathrm{MTU}$ to $5 \mathrm{GWd} / \mathrm{MTU}$ and was significantly expanded for most of the fission product isotopes.

A conservative approach was used to compensate for the effects of unknown uncertainties associated with the extension of the area of applicability of the validation data. The extension of the area of applicability was performed simultaneously with augmentation of the bias uncertainty values by using two-sided tolerance-limit factors as multiplication factors (see Sect. 6.3.1 and Appendix A.1), thereby increasing the uncertainty in $k_{\text {eff }}$ due to depletion uncertainty. Statistical tolerance limits are values such that the probability is equal to $\gamma$ that the limits include at least a proportion $p$ of the population.

Tolerance-limit factors depend on the type of the distribution and on the sample size. The value of the tolerance-limit factor increases as the sample size decreases. The values applied to the calculated sample standard deviation correspond to $95 \%$ certainty and $68.27 \%$ of the population and vary from 1.126 (118 samples) to 1.459 (17 samples) (see Appendix A.1). Therefore, a larger augmentation was applied to the uncertainties in the calculated fission product concentrations than the augmentation applied to the uncertainties in the calculated actinide concentrations. However, the effect on $k_{\text {eff }}$ of additional uncertainties introduced by extending of the area of applicability of the validation data for fission product isotopes diminishes with decreasing burnup because $k_{\text {eff }}$ sensitivity to fission product cross section decreases with decreasing burnup (see Ref. 33, Table 4.1).

The use of two-sided tolerance-limit factors as augmentation factors for the calculated standard deviation of the $\mathrm{M} / \mathrm{C}$ isotopic concentration values is also intended to account for potential uncertainties associated with the identified non-normality of frequency distributions and dependence on burnup for some burnup credit isotopes. This approach appears to adequately account for the various additional uncertainty sources associated with the isotopic validation process. For illustrative purposes, the validation data for ${ }^{235} \mathrm{U}$ and ${ }^{240} \mathrm{Pu}$ are discussed further. The frequency distribution of the $\mathrm{M} / \mathrm{C}$ isotopic concentration values for ${ }^{235} \mathrm{U}$ is highly peaked since $81 \%$ of the $\mathrm{M} / \mathrm{C}$ isotopic concentration values fall within one standard deviation. However, as illustrated in Fig. 4 , the $3 \sigma$ sampling interval contains $98 \%$ of the values, which is adequately close to the ideal $99.73 \%$ expected for the normal distribution. A linear dependency of the $\mathrm{M} / \mathrm{C}$ isotopic concentration values on burnup was identified for eight burnup-credit isotopes, including ${ }^{240} \mathrm{Pu}$. The downward trend in the $\mathrm{M} / \mathrm{C}$ isotopic concentration values as a function of burnup is clearly noticeable for ${ }^{240} \mathrm{Pu}$ on the graph shown in Fig. 5 (a). The $3 \sigma$ sampling interval used in this calculation for ${ }^{240} \mathrm{Pu}$ is illustrated in Fig. 5 (a) and contains $100 \%$ of the $\mathrm{M} / \mathrm{C}$ isotopic concentration values. Fig. 5 (b) shows that the sampling interval would be smaller (i.e., less conservative for criticality) if the $\mathrm{M} / \mathrm{C}$ isotopic concentration values for the evaluated samples in the TMI-1 assembly NJ05YU were excluded from the validation data set on the basis of their atypical characteristics. The error bars in Fig. 4 and Fig. 5 indicate the reported measurement (one sigma) uncertainty. 
Table 9. Isotopic bias and bias uncertainty values

\begin{tabular}{|c|c|c|c|c|c|c|}
\hline Isotope & $\bar{X}_{i}^{a}$ & $s_{i}$ & $\begin{array}{l}\text { Frequency within } \\
\qquad \bar{X}_{i} \pm s_{i} \\
(\%)\end{array}$ & $\begin{array}{l}\text { Frequency within } \\
\qquad \begin{array}{c}\bar{X}_{i} \pm 2 s_{i} \\
(\%)\end{array}\end{array}$ & $\begin{array}{c}\text { Frequency within } \\
\begin{array}{c}\bar{X}_{i} \pm 3 s_{i} \\
(\%)\end{array}\end{array}$ & $\sigma_{i}^{a, b}$ \\
\hline${ }^{234} \mathrm{U}$ & 0.9348 & 0.1254 & 70 & 93 & 100 & 0.1470 \\
\hline${ }^{235} \mathrm{U}$ & 0.9934 & 0.0517 & 81 & 94 & 98 & 0.0582 \\
\hline${ }^{236} \mathrm{U}$ & 1.0069 & 0.0373 & 70 & 94 & 99 & 0.0420 \\
\hline${ }^{238} \mathrm{U}$ & 1.0014 & 0.0035 & 88 & 93 & 95 & 0.0040 \\
\hline${ }^{237} \mathrm{~Np}$ & 0.9485 & 0.1340 & 76 & 92 & 98 & 0.1631 \\
\hline${ }^{238} \mathrm{Pu}$ & 1.0758 & 0.1091 & 77 & 95 & 98 & 0.1241 \\
\hline${ }^{239} \mathrm{Pu}$ & 0.9526 & 0.0528 & 75 & 95 & 99 & 0.0595 \\
\hline${ }^{240} \mathrm{Pu}$ & 0.9668 & 0.0488 & 78 & 94 & 98 & 0.0550 \\
\hline${ }^{241} \mathrm{Pu}$ & 1.0065 & 0.0643 & 71 & 95 & 98 & 0.0724 \\
\hline${ }^{242} \mathrm{Pu}$ & 1.0071 & 0.0763 & 75 & 94 & 98 & 0.0859 \\
\hline${ }^{241} \mathrm{Am}$ & 0.9795 & 0.2143 & 69 & 98 & 98 & 0.2555 \\
\hline${ }^{242 \mathrm{~m}} \mathrm{Am}$ & 0.9320 & 0.2173 & 75 & 93 & 100 & 0.2678 \\
\hline${ }^{243} \mathrm{Am}$ & 0.8745 & 0.1654 & 73 & 98 & 98 & 0.1999 \\
\hline${ }^{95} \mathrm{Mo}$ & 0.9935 & 0.0610 & 61 & 94 & 100 & 0.0878 \\
\hline${ }^{99} \mathrm{Tc}$ & 0.9203 & 0.1306 & 77 & 97 & 97 & 0.1690 \\
\hline${ }^{101} \mathrm{Ru}$ & 0.9452 & 0.0798 & 72 & 89 & 100 & 0.1147 \\
\hline${ }^{103} \mathrm{Rh}$ & 0.9240 & 0.1084 & 68 & 95 & 95 & 0.1540 \\
\hline${ }^{109} \mathrm{Ag}$ & 0.5507 & 0.2009 & 71 & 94 & 100 & 0.2931 \\
\hline${ }^{143} \mathrm{Nd}$ & 0.9742 & 0.0439 & 72 & 94 & 100 & 0.0533 \\
\hline${ }^{145} \mathrm{Nd}$ & 0.9812 & 0.0275 & 78 & 94 & 100 & 0.0333 \\
\hline${ }^{147} \mathrm{Sm}$ & 0.9890 & 0.0759 & 75 & 94 & 100 & 0.0961 \\
\hline${ }^{149} \mathrm{Sm}$ & 0.8885 & 0.0694 & 66 & 94 & 100 & 0.0893 \\
\hline${ }^{150} \mathrm{Sm}$ & 0.9442 & 0.0534 & 78 & 94 & 100 & 0.0676 \\
\hline${ }^{151} \mathrm{Sm}$ & 0.7486 & 0.0560 & 72 & 97 & 100 & 0.0709 \\
\hline${ }^{152} \mathrm{Sm}$ & 0.7888 & 0.0612 & 67 & 97 & 100 & 0.0775 \\
\hline${ }^{151} \mathrm{Eu}$ & 1.0688 & 0.3831 & 78 & 96 & 100 & 0.5225 \\
\hline${ }^{153} \mathrm{Eu}$ & 0.9735 & 0.0727 & 60 & 100 & 100 & 0.0945 \\
\hline${ }^{155} \mathrm{Gd}$ & 1.7161 & 0.3452 & 77 & 97 & 97 & 0.4491 \\
\hline
\end{tabular}

${ }^{a}$ Isotopic bias and the uncertainty associated with the bias used in the Monte Carlo uncertainty sampling calculations.

${ }^{b}$ The product of sample standard deviation and the two-sided tolerance limit factor for $95 \%$ certainty and $68.27 \%$ of the population. The values for tolerance-limit factors were calculated in spreadsheet $\mathrm{DVD} / \mathrm{xls} /$ validation.xls, worksheet $t l$-factors. 


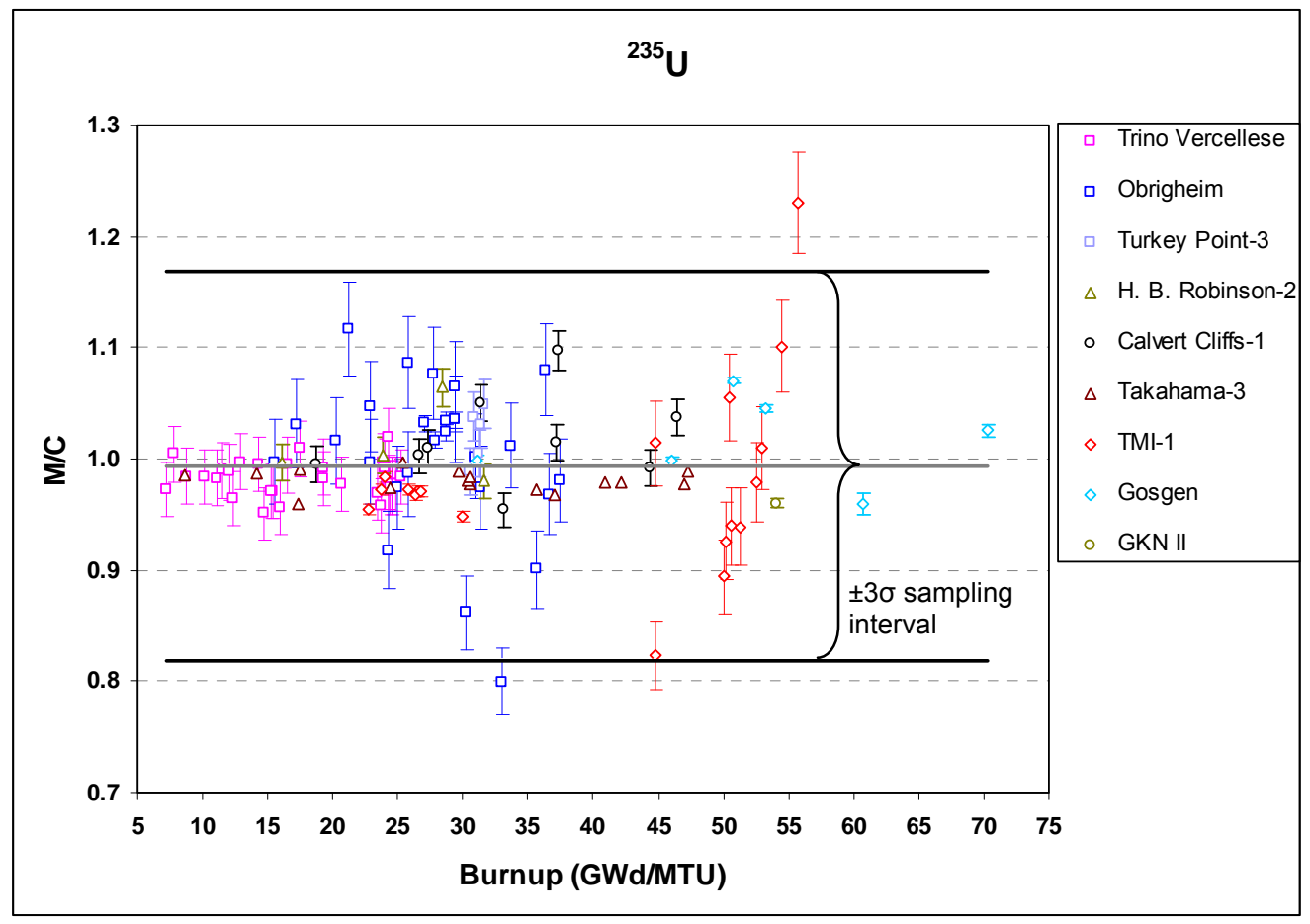

Fig. 4. $\mathrm{M} / \mathrm{C}$ isotopic concentration ratio as a function of burnup and the sampling interval for ${ }^{235} \mathrm{U}$. 


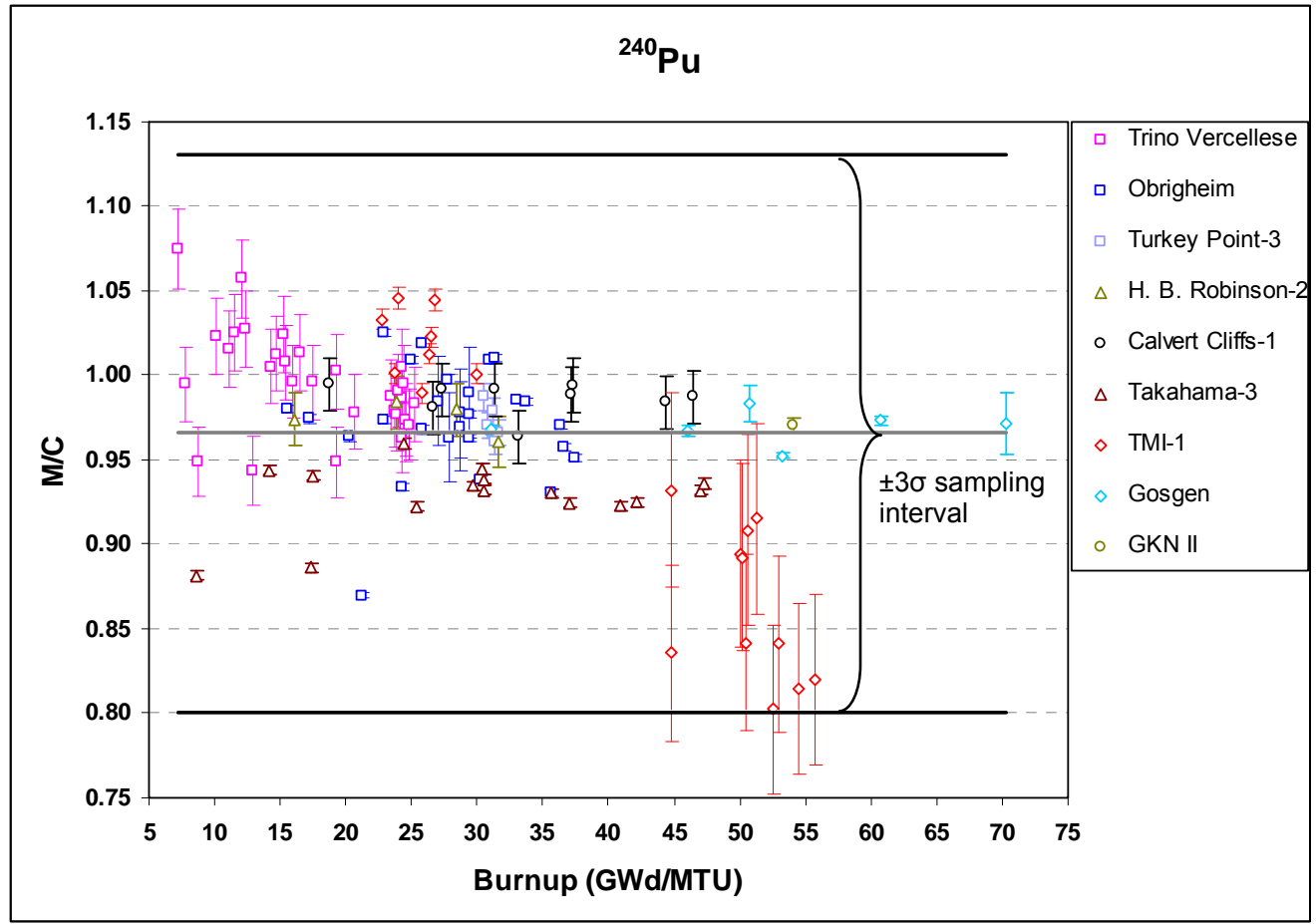

(a)

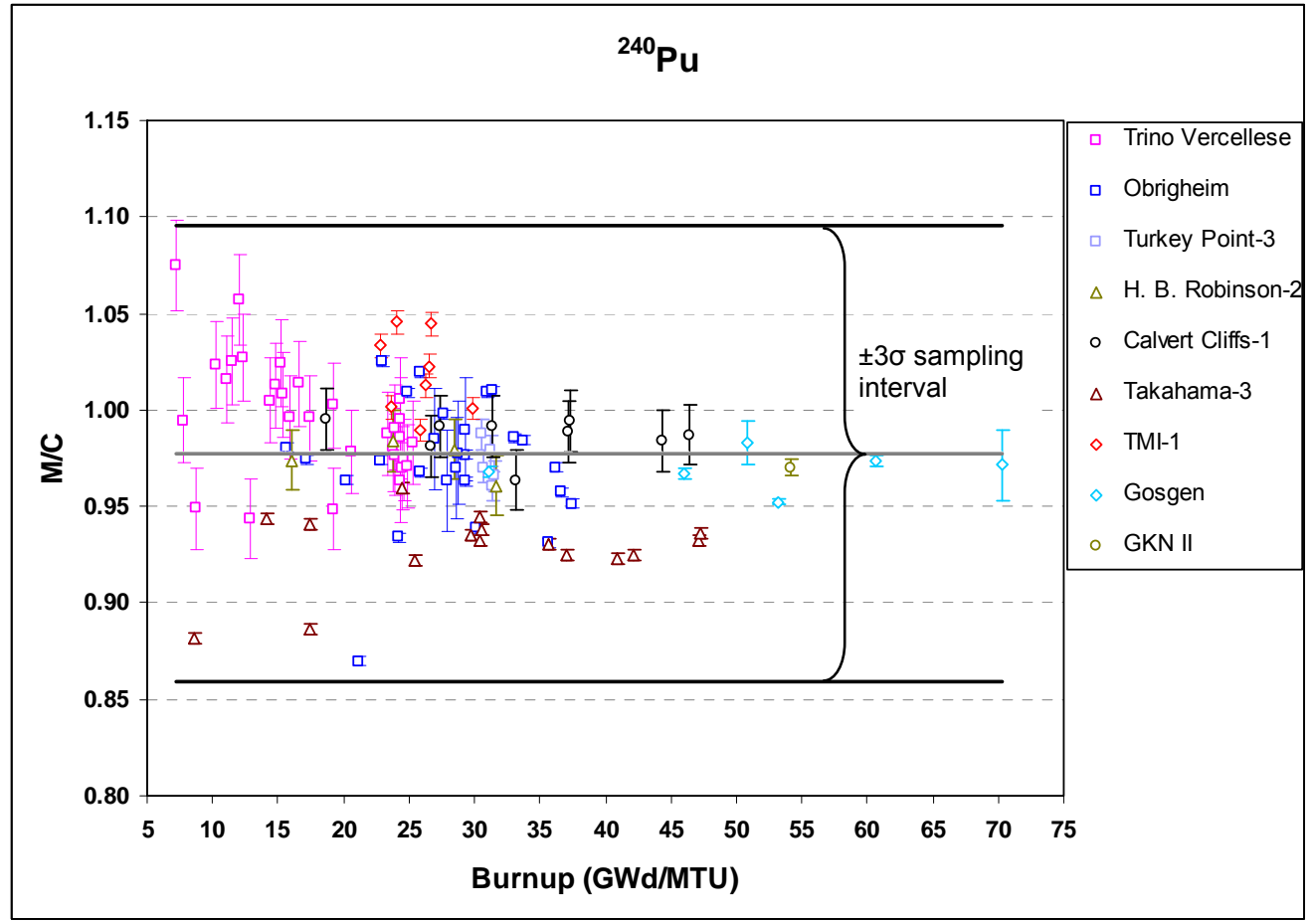

(b)

Fig. 5. M/C isotopic concentration ratio as a function of burnup and the sampling interval for ${ }^{240} \mathrm{Pu}$ based on (a) entire set of evaluated spent fuel samples and (b) the set of evaluated spent fuel samples without the samples from TMI-1 assembly NJ05YU. 


\subsection{DESCRIPTION OF THE MCNP MODEL FOR WASTE PACKAGES}

The PWR waste package configuration consists of 21 fully-flooded, intact B\&W $15 \times 15$ fuel assemblies, intact fuel tubes, and borated stainless steel plates placed inside a conceptual transport/aging/disposal (TAD) canister waste package configuration and reflected by tuff, simulating the repository environment. A horizontal cross section of the MCNP model for the PWR waste package is shown in Fig. 6. The thickness of the absorber plate in the model is $6 \mathrm{~mm}$, as compared to $11 \mathrm{~mm}$ for intact absorber plates, to account for possible absorber plate corrosion over 10,000 years. The ${ }^{10} \mathrm{~B}$ weight fraction in the models is $75 \%$ of the actual fraction for consistency with the guidance in NUREG-1536 (Ref. 34). The conservative PWR waste package model with respect to criticality was used in the development of loading curves for commercial SNF TAD canisters (Ref. 18). The MCNP input files for the current criticality calculations are based on the MCNP input file $d 0 a 00$ for a PWR waste package (DTN: MO0711LOADCURV.000, Ref. 18). In the MCNP model, the fuel is represented as a single axial zone with uniform isotopic compositions. The oneaxial-zone fuel representation appears to be slightly more conservative than the sevenaxial-zone representation for the majority of PWR SNF with potential for waste package criticality based on a comparison study considering the two fuel axial representations (see Ref. 18, Fig. 6-9).

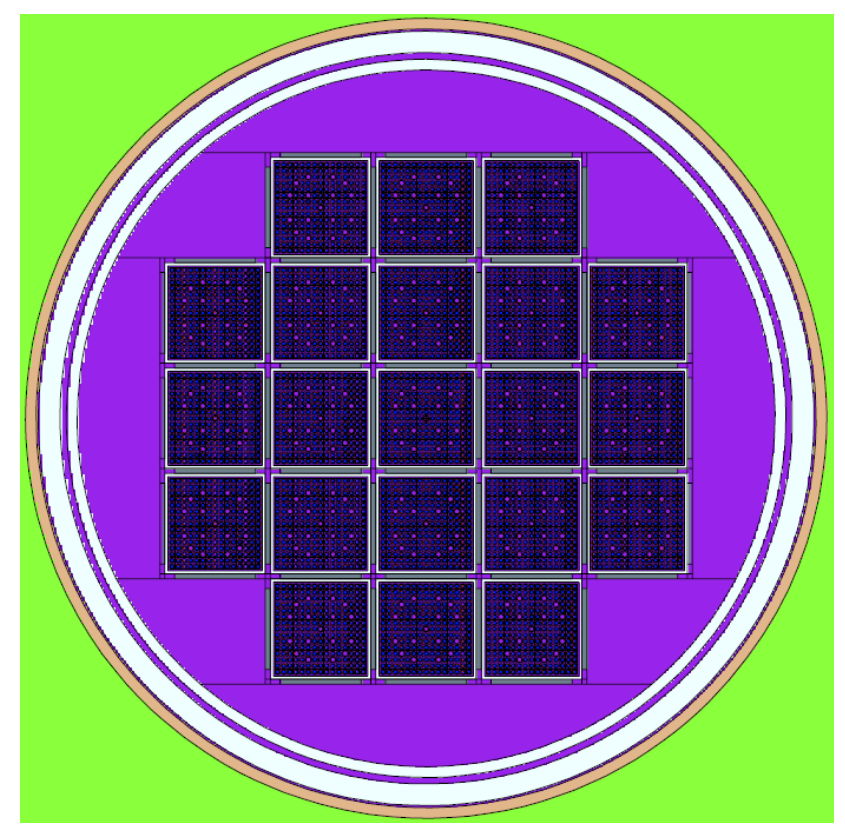

Fig. 6. Horizontal cross section of the MCNP model for the PWR waste package.

\subsubsection{Selected Fuel Initial Enrichment, Burnup, and Decay Time for Criticality Calculations}

The fuel isotopic compositions selected for criticality calculations correspond to the following combinations of fuel initial enrichment, in wt $\%{ }^{235} \mathrm{U}$, and burnup, in GWd/MTU: 2.5/10, 3/15, $3.5 / 25,4 / 30,4.5 / 35$, and 5/40, for SNF cooling times of 5, 100, and 10,000 years. The initial enrichment and burnup combinations characterize data points in the proximity of the loading curve established for PWR waste packages in Ref. 18, Table 6-26 and Figure 6-24. The burnup values for the six initial enrichment-burnup combinations represent the nearest integers obtained by either rounding up or rounding down the burnup values in Ref. 18, Table 6-26. The critical limit used in the loading curve analysis in Ref. 18 is based on the isotopic bias in predicted nuclide composition using the one-dimensional depletion analysis code SAS2H in SCALE 4.4a (Ref. 28). For the 5-year cooling time only, the burnup was also varied by $\pm 5 \mathrm{GWd} / \mathrm{MTU}$ to observe the sensitivity of the $k_{\text {eff }}$ uncertainty values to data points in the proximity of the established loading curve. The SCALE ft71f001 binary files are available in the DVD/TRITON.zip archive (refer to the *.den files) to facilitate ORIGEN decay calculations for other decay time values. 



\section{RESULTS}

The results obtained for $\Delta k_{I S O}$, the penalty in waste package reactivity due to bias and uncertainty in calculated SNF isotopic compositions (see Sect. 6.1), are summarized in Table 10, Table 11, and Table 12 for PWR SNF at 5-, 100-, and 10,000-year cooling times, respectively, and for six combinations of initial enrichment and burnup characterizing data points in the proximity of the loading curve established for disposal of PWR SNF (see Sect. 7.3.1). Additional combinations of initial enrichment and burnup were considered for the SNF at 5-year cooling time, as shown in Table 10 , to determine the sensitivity of $\Delta k_{I S O}$ to the burnup values in the proximity of the loading curve. The 100-, and 10,000-year cooling time compositions were analyzed to determine whether the $\Delta k_{I S O}$ values increase with increasing cooling time and whether the increase in the $\Delta k_{I S O}$ values is sufficient to offset the decrease in $k_{\text {eff }}$ values that occurs with increasing cooling time.

The Monte Carlo uncertainty sampling method (see Sect. 6.3) allows compensating effects of positive and negative changes in system reactivity due to statistical corrections for isotopic bias and bias uncertainty. The $\Delta k_{I S O}$ results are based on a minimum of $200 \mathrm{MCNP}$ calculations for each combination of fuel initial enrichment, burnup, and cooling time, using fuel isotopic compositions stochastically corrected for bias uncertainty according to the established frequency distributions of the isotopic validation data (see Sect. 7.2). The $\Delta k_{I S O}$ values determined in this calculation are based on the upper tolerance limit for $95 \%$ of the $k_{\text {eff }}$ population and $95 \%$ certainty [see Eq. (11)].

Tables 10 through 12 provide the calculation results for the following:

- the effective neutron multiplication factor $k_{\text {eff }}$ based on unadjusted predicted isotopic compositions;

- the effective neutron multiplication factor based on predicted isotopic compositions corrected for isotopic bias, $k_{\text {eff }-B E}$;

- the statistical uncertainty in $k_{\text {eff }-B E}$ due to isotopic bias uncertainty, $\Delta k_{\text {eff }-M C}$ [see Eq. (10)];

- the penalty in reactivity due to isotopic composition bias and uncertainty in calculated nuclide compositions, $\Delta k_{I S O}$ [see Eq. (11)]; and

- the bounding effective neutron multiplication factor based on the most unfavorable combination of isotopic bias uncertainty, $k_{\text {eff-bounding }}$ [see Eq. (15)].

The $k_{\text {eff-BE }}-k_{\text {eff }}$ component of Eq. 11 represents the effect on $k_{\text {eff }}$ of the corrections for isotopic bias. The results summarized in Tables 10 through 12 show that $\Delta k_{I S O}$ values vary to a small degree with fuel enrichment, burnup, and cooling time since fuel isotopic composition depends on these parameters. The variation of fuel isotopic concentration with time is illustrated in Fig. 7 for PWR SNF of 5.0-wt $\%{ }^{235} \mathrm{U}$ initial enrichment and 40-GWd/MTU burnup.

For the selected SNF compositions with potential for criticality corresponding to the 5-year cooling time, the values obtained for $k_{\text {eff-BE }}-k_{\text {eff }}$ were almost negligible as compared to the $k_{\text {eff }}$ values (less than $0.4 \%$ ); the $\Delta k_{e f f-M C}$ values varied from 0.0114 to 0.0134 ; and the $\Delta k_{I S O}$ values varied from 0.0188 to 0.0244 . The average $\Delta k_{I S O}$ value was 0.0215 . The $\Delta k_{I S O}$ values represent 1.97 to $2.45 \%$ of the corresponding $k_{\text {eff }}$ values based on predicted spent fuel compositions, with an average value of $2.26 \%$. The largest $\Delta k_{I S O}$ value was obtained for the SNF composition corresponding to 2.5 -wt $\%$ 
${ }^{235} \mathrm{U}$ initial enrichment and 5-GWd/MTU burnup. However, the isotopic bias and uncertainty in predicted fuel compositions for very low burnup are expected to be fairly small since these compositions are mainly dominated by the uranium isotopes. In the case of this calculation, the extension of the applicability of the isotopic validation data based on fuel samples with a broad range of burnup values (up to $70 \mathrm{GWd} / \mathrm{MTU}$ ) to very low burnup values (e.g., $5 \mathrm{GWd} / \mathrm{MTU}$ ) is considered to have an unrealistically penalizing effect. Therefore, the $\Delta k_{I S O}$ value of 0.0229 obtained for the SNF composition corresponding to 3.5 -wt $\%{ }^{235} \mathrm{U}$ initial enrichment and $25-\mathrm{GWd} / \mathrm{MTU}$ burnup is considered to be a more realistic bounding value. For very low burnup (e.g., $<10 \mathrm{GWd} / \mathrm{MTU}$ ), criticality safety analyses based on the fresh fuel assumption are justified because (1) very few RCA data for low burnup fuel are available for use in isotopic validation studies and (2) the impact of assembly design and operation variability on SNF compositions for low burnup is more significant than on the SNF compositions for higher burnup.

For the 100-year cooling time isotopic compositions, the values of $k_{\text {eff-BE }}-k_{\text {eff }}$ varied from -0.0033 to -0.0065 ; the $\Delta k_{e f f-M C}$ values varied from 0.0138 to 0.0175 ; and the $\Delta k_{I S O}$ values varied from 0.0224 to 0.0281 . Although the $\Delta k_{I S O}$ values for 100-year cooling time are higher than those obtained for the 5-year cooling time, the increase is insufficient to offset the decrease in $k_{\text {eff }}$ that occurs with increasing cooling time. For the 10,000-year cooling time isotopic compositions, the values of $k_{\text {eff }-B E}-k_{\text {eff }}$ varied from -0.0037 to -0.0070 ; the $\Delta k_{\text {eff }-M C}$ values varied from 0.0124 to 0.0146 ; and the $\Delta k_{I S O}$ values varied from 0.0200 to 0.0217 .

For comparison purposes only, the values of the penalty in reactivity due to isotopic composition bias and uncertainty based on the bounding method (see Sect. 6.4) are also provided in Table 10 through Table 12. As expected, the bounding method produces significantly larger bias values than the Monte Carlo uncertainty sampling method (e.g., 0.0557 versus 0.0221 for the SNF composition corresponding to the 5 -wt $\%{ }^{235} \mathrm{U}$ initial enrichment, $45-\mathrm{GWd} / \mathrm{MTU}$ burnup, and 5-year cooling time) because this method maximizes the effects of isotopic composition bias uncertainties on system reactivity. The significant conservatism of the bounding method is not justified when this method is coupled with the use of conservative depletion parameters that maximize the spent fuel residual reactivity, which is the case of the disposal criticality analysis methodology.

The results of the Monte Carlo uncertainty sampling method are not always intuitive due to the nature of the method itself, which allows for compensating positive and negative reactivity effects produced by varying isotopic uncertainties. The compensating effects appear to be more effective in the case of SNF compositions for which the reactivity worth of the fission product isotopes becomes significant (e.g., SNF compositions for 5-year cooling time and higher burnup) as compared to the case of SNF compositions dominated by main actinide isotopes (e.g., SNF compositions for very low burnup or for larger cooling times). 
Table 10. $\Delta k_{\text {ISo }}$ for waste packages containing PWR SNF at 5 years after discharge

\begin{tabular}{|c|c|c|c|c|c|c|}
\hline $\begin{array}{c}\text { Enrichment } \\
\left.\text { (wt \% }{ }^{235} \mathrm{U}\right) / \text { burnup } \\
\text { (GWd/MTU) }\end{array}$ & $2.5 / 10$ & $3.0 / 15$ & $3.5 / 25$ & $4.0 / 30$ & $4.5 / 35$ & $5.0 / 40$ \\
\hline$k_{\text {eff }}^{a, b}$ & 0.9588 & 0.9674 & 0.9381 & 0.9416 & 0.9437 & 0.9440 \\
\hline$k_{e f f-B E}^{a, c}$ & 0.9577 & 0.9660 & 0.9373 & 0.9411 & 0.9423 & 0.9435 \\
\hline$k_{\text {eff }-B E}-k_{\text {eff }}{ }^{d}$ & -0.0011 & -0.0014 & -0.0008 & -0.0005 & -0.0014 & -0.0005 \\
\hline$\Delta k_{e f f-M C}^{e}$ & 0.0118 & 0.0122 & 0.0124 & 0.0114 & 0.0118 & 0.0119 \\
\hline$\Delta k_{e f f-M C} \times k_{1}^{f}$ & 0.0217 & 0.0224 & 0.0228 & 0.0210 & 0.0217 & 0.0219 \\
\hline$k_{e f f-B E}+\Delta k_{e f f-M C} \times k_{1}$ & 0.9794 & 0.9884 & 0.9601 & 0.9621 & 0.9640 & 0.9654 \\
\hline$\Delta k_{I S O}{ }^{g}$ & 0.0215 & 0.0219 & 0.0229 & 0.0213 & 0.0212 & 0.0222 \\
\hline$\Delta k_{I S O} / k_{\text {eff }}(\%)$ & 2.24 & 2.26 & 2.44 & 2.26 & 2.24 & 2.36 \\
\hline$k_{\text {eff-bounding }}{ }^{a, h}$ & 0.9966 & 1.0085 & 0.9857 & 0.9919 & 0.9950 & 0.9979 \\
\hline$k_{\text {eff-bounding }}-k_{\text {eff }}$ & 0.0378 & 0.0411 & 0.0476 & 0.0503 & 0.0513 & 0.0539 \\
\hline $\begin{array}{c}\text { Enrichment } \\
\left.\text { (wt \% }{ }^{235} \mathrm{U}\right) / \text { burnup } \\
\text { (GWd/MTU) }\end{array}$ & $2.5 / 5$ & $3.0 / 10$ & $3.5 / 20$ & $4.0 / 25$ & $4.5 / 30$ & $5.0 / 35$ \\
\hline$k_{\text {eff }}^{a, b}$ & 0.9958 & 1.0040 & 0.9710 & 0.9734 & 0.9731 & 0.9726 \\
\hline$k_{e f f-B E}^{a, c}$ & 0.9947 & 1.0016 & 0.9704 & 0.9724 & 0.9726 & 0.9727 \\
\hline$k_{e f f-B E}-k_{\text {eff }}{ }^{d}$ & -0.0011 & -0.0024 & -0.0006 & -0.0010 & -0.0005 & 0.0001 \\
\hline$\Delta k_{e f f-M C}^{e}$ & 0.0134 & 0.0116 & 0.0113 & 0.0123 & 0.0116 & 0.0111 \\
\hline$\Delta k_{e f f-M C} \times k_{1}^{f}$ & 0.0247 & 0.0213 & 0.0208 & 0.0226 & 0.0213 & 0.0204 \\
\hline$k_{e f f-B E}+\Delta k_{e f f-M C} \times k_{1}$ & 1.0194 & 1.0229 & 0.9912 & 0.9950 & 0.9939 & 0.9931 \\
\hline$\Delta k_{I S O}{ }^{g}$ & 0.0244 & 0.0198 & 0.0210 & 0.0225 & 0.0217 & 0.0214 \\
\hline$\Delta k_{I S O} / k_{\text {eff }}(\%)$ & 2.45 & 1.97 & 2.17 & 2.31 & 2.23 & 2.20 \\
\hline$k_{\text {eff-bounding }}{ }^{a, h}$ & 1.0296 & 1.0401 & 1.0145 & 1.0188 & 1.0215 & 1.0229 \\
\hline$k_{\text {eff-bounding }}-k_{\text {eff }}$ & 0.0338 & 0.0361 & 0.0435 & 0.0454 & 0.0484 & 0.0503 \\
\hline
\end{tabular}


Table 10 (continued)

\begin{tabular}{|c|c|c|c|c|c|c|}
\hline $\begin{array}{c}\text { Enrichment } \\
\left.\text { (wt \% }{ }^{235} \mathrm{U}\right) / \text { burnup } \\
\text { (GWd/MTU) }\end{array}$ & $2.5 / 15$ & $3.0 / 20$ & $3.5 / 30$ & $4.0 / 35$ & $4.5 / 40$ & $5.0 / 45$ \\
\hline$k_{\text {eff }}^{a, b}$ & 0.9234 & 0.9323 & 0.9067 & 0.9124 & 0.9141 & 0.9162 \\
\hline$k_{e f f-B E}{ }^{a, c}$ & 0.9202 & 0.9311 & 0.9051 & 0.9103 & 0.9136 & 0.9156 \\
\hline$k_{e f f-B E}-k_{\text {eff }}{ }^{d}$ & -0.0032 & -0.0012 & -0.0016 & -0.0021 & -0.0005 & -0.0006 \\
\hline$\Delta k_{e f f-M C}^{e}$ & 0.0116 & 0.0118 & 0.0128 & 0.0109 & 0.0112 & 0.0119 \\
\hline$\Delta k_{e f f-M C} \times k_{1}^{f}$ & 0.0213 & 0.0217 & 0.0236 & 0.0201 & 0.0206 & 0.0219 \\
\hline$k_{e f f-B E}+\Delta k_{e f f-M C} \times k_{1}$ & 0.9415 & 0.9528 & 0.9287 & 0.9304 & 0.9342 & 0.9375 \\
\hline$\Delta k_{I S O}{ }^{g}$ & 0.0190 & 0.0214 & 0.0222 & 0.0188 & 0.0210 & 0.0221 \\
\hline$\Delta k_{I S O} / k_{e f f}(\%)$ & 2.06 & 2.29 & 2.45 & 2.06 & 2.29 & 2.42 \\
\hline$k_{\text {eff-bounding }}{ }^{a, h}$ & 0.9651 & 0.9774 & 0.9586 & 0.9647 & 0.9703 & 0.9739 \\
\hline$k_{\text {eff-bounding }}-k_{\text {eff }}$ & 0.0417 & 0.0451 & 0.0519 & 0.0523 & 0.0562 & 0.0577 \\
\hline
\end{tabular}

${ }^{a}$ The standard deviation for an MCNP $k_{\text {eff }}$ value is 0.0003 .

${ }^{b} k_{\text {eff }}$ values obtained by using predicted isotopic compositions.

${ }^{c}$ Best estimate $k_{\text {eff }}$ values obtained by using predicted isotopic compositions corrected for isotopic bias (predicted isotopic concentrations multiplied by the isotopic bias values).

${ }^{d}$ The standard uncertainty associated with the $k_{e f f-B E}-k_{\text {eff }}$ values is approximately 0.0004 .

${ }^{e}$ Bias uncertainty determined by using the Monte Carlo uncertainty sampling method [see Eq. (10)].

${ }^{f} k_{l}$ is the tolerance-limit factor for the one-sided tolerance interval, assuming 200 samples, $95 \%$ of the population, and $95 \%$ certainty, whose value is 1.84 .

${ }^{g}$ Values calculated using Eq. (11).

${ }^{h}$ Bounding $k_{\text {eff }}$ limit based on the most unfavorable combination of isotopic uncertainty [see Eq. (15)]. 
Table 11. $\Delta \boldsymbol{k}_{\text {ISo }}$ for waste packages containing PWR SNF at 100 years after discharge

\begin{tabular}{|c|c|c|c|c|c|c|}
\hline $\begin{array}{c}\text { Enrichment } \\
\left.\text { (wt \% }{ }^{235} \mathrm{U}\right) / \text { burnup } \\
\text { (GWd/MTU) }\end{array}$ & $2.5 / 10$ & 3.0/15 & $3.5 / 25$ & $4.0 / 30$ & $4.5 / 35$ & $5.0 / 40$ \\
\hline$k_{e f f}^{a, b}$ & 0.9403 & 0.9392 & 0.8902 & 0.8878 & 0.8853 & 0.8833 \\
\hline$k_{e f f-B E}^{a, c}$ & 0.9370 & 0.9355 & 0.8853 & 0.8833 & 0.8804 & 0.8768 \\
\hline$k_{e f f-B E}-k_{e f f}{ }^{d}$ & -0.0033 & -0.0037 & -0.0049 & -0.0045 & -0.0049 & -0.0065 \\
\hline$\Delta k_{e f f-M C}^{e}$ & 0.0138 & 0.0137 & 0.0145 & 0.0163 & 0.0175 & 0.0166 \\
\hline$\Delta k_{e f f-M C} \times k_{1}^{f}$ & 0.0254 & 0.0252 & 0.0267 & 0.0300 & 0.0322 & 0.0305 \\
\hline$k_{e f f-B E}+\Delta k_{e f f-M C} \times k_{1}$ & 0.9624 & 0.9607 & 0.9120 & 0.9133 & 0.9126 & 0.9073 \\
\hline$\Delta k_{I S O}{ }^{g}$ & 0.0229 & 0.0224 & 0.0226 & 0.0263 & 0.0281 & 0.0249 \\
\hline$k_{\text {eff-bounding }}{ }^{a, h}$ & 0.9828 & 0.9869 & 0.9473 & 0.9488 & 0.9489 & 0.9498 \\
\hline$k_{\text {eff-bounding }}-k_{\text {eff }}$ & 0.0425 & 0.0477 & 0.0571 & 0.0610 & 0.0636 & 0.0665 \\
\hline
\end{tabular}

${ }^{a}$ The standard deviation for an MCNP $k_{\text {eff }}$ value is 0.0003 .

${ }^{b} k_{e f f}$ values obtained by using predicted isotopic compositions.

${ }^{c}$ Best estimate $k_{e f f}$ values obtained by using predicted isotopic compositions corrected for isotopic bias (predicted isotopic concentrations multiplied by the isotopic bias values).

${ }^{d}$ The standard uncertainty associated with the $k_{e f f-B E}-k_{e f f}$ values is approximately 0.0004 .

${ }^{e}$ Bias uncertainty determined by using the Monte Carlo uncertainty sampling method [see Eq. (10)].

${ }^{f} k_{l}$ is the tolerance-limit factor for the one-sided tolerance interval, assuming 200 samples, $95 \%$ of the population, and $95 \%$ certainty, whose value is 1.84 .

${ }^{g}$ Values calculated using Eq. (11).

${ }^{h}$ Bounding $k_{\text {eff }}$ limit based on the most unfavorable combination of isotopic uncertainty [see Eq. (15)]. 
Table 12. $\Delta k_{\text {ISO }}$ for waste packages containing PWR SNF at 10,000 years after discharge

\begin{tabular}{|c|c|c|c|c|c|c|}
\hline $\begin{array}{c}\text { Enrichment } \\
\left.\text { (wt \% }{ }^{235} \mathrm{U}\right) / \text { burnup } \\
\text { (GWd/MTU) }\end{array}$ & $2.5 / 10$ & 3.0/15 & $3.5 / 25$ & $4.0 / 30$ & 4.5/35 & $5.0 / 40$ \\
\hline$k_{e f f}^{a, b}$ & 0.9540 & 0.9601 & 0.9203 & 0.9225 & 0.9232 & 0.9231 \\
\hline$k_{e f f-B E}^{a, c}$ & 0.9503 & 0.9557 & 0.9146 & 0.9165 & 0.9172 & 0.9161 \\
\hline$k_{e f f-B E}-k_{e f f}{ }^{d}$ & -0.0037 & -0.0044 & -0.0057 & -0.0060 & -0.0060 & -0.0070 \\
\hline$\Delta k_{e f f-M C}^{e}$ & 0.0124 & 0.0137 & 0.0141 & 0.0137 & 0.0146 & 0.0144 \\
\hline$\Delta k_{\text {eff-MC }} \times k_{1}^{f}$ & 0.0228 & 0.0252 & 0.0259 & 0.0252 & 0.0269 & 0.0265 \\
\hline$k_{e f f-B E}+\Delta k_{e f f-M C} \times k_{1}$ & 0.9731 & 0.9809 & 0.9405 & 0.9417 & 0.9441 & 0.9426 \\
\hline$\Delta k_{I S O}^{g}$ & 0.0200 & 0.0217 & 0.0211 & 0.0201 & 0.0217 & 0.0203 \\
\hline$k_{\text {eff-bounding }}{ }^{a, h}$ & 0.9943 & 1.0026 & 0.9712 & 0.9751 & 0.9776 & 0.9800 \\
\hline$k_{\text {eff-bounding }}-k_{\text {eff }}$ & 0.0403 & 0.0425 & 0.0509 & 0.0526 & 0.0544 & 0.0569 \\
\hline
\end{tabular}

${ }^{a}$ The standard deviation for an MCNP $k_{\text {eff }}$ value is 0.0003 .

${ }^{b} k_{\text {eff }}$ values obtained by using predicted isotopic compositions.

${ }^{c}$ Best estimate $k_{\text {eff }}$ values obtained by using predicted isotopic compositions corrected for isotopic bias (predicted isotopic concentrations multiplied by the isotopic bias values).

${ }^{d}$ The standard uncertainty associated with the $k_{\text {eff }-B E}-k_{\text {eff }}$ values is approximately 0.0004 .

${ }^{e}$ Bias uncertainty determined by using the Monte Carlo uncertainty sampling method [see Eq. (10)].

${ }^{f} k_{l}$ is the tolerance-limit factor for the one-sided tolerance interval, assuming 200 samples, 95 percentage of the population, and $95 \%$ certainty, whose values is 1.84 .

${ }^{g}$ Values calculated using Eq. (11).

${ }^{h}$ Bounding $k_{\text {eff }}$ limit based on the most unfavorable combination of isotopic uncertainty [see Eq. (15)]. 


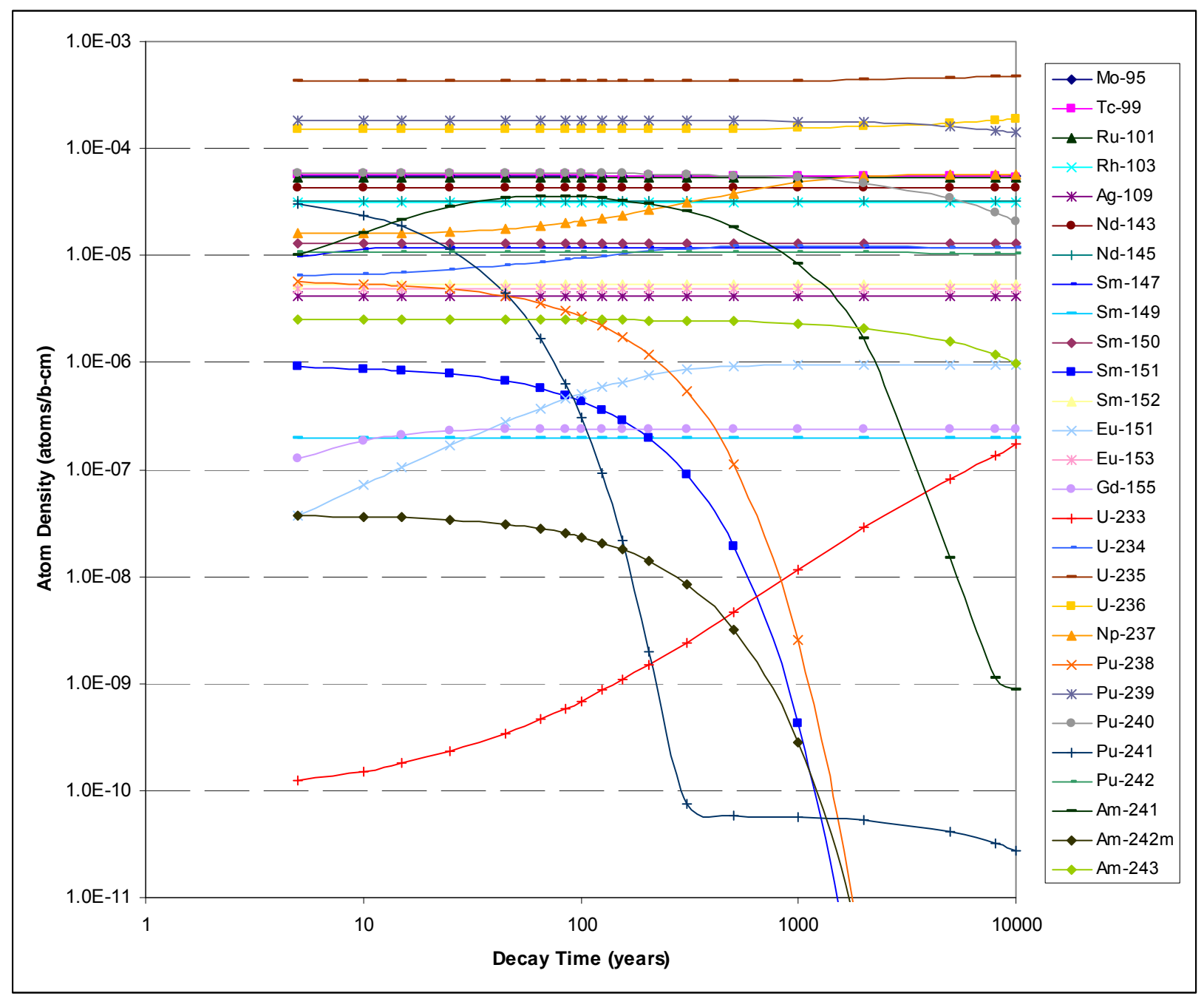

Fig. 7. Isotopic concentration versus time after discharge for PWR SNF of 5.0-wt $\%{ }^{235} \mathrm{U}$ initial enrichment and 40-GWd/MTU burnup. 



\section{SUMMARY}

The disposal criticality analysis methodology is based on burnup credit. ${ }^{1}$ The burnup-credit methodology requires validation of both the depletion method (SCALE 5.1) used to calculate the concentrations of the credited actinide and fission product isotopes in SNF compositions and the criticality method (MCNP 5.1.40) used to calculate the $k_{\text {eff }}$ values for waste packages. The results of the validation studies are used to establish a critical limit at which waste packages are considered potentially critical. The validation of the criticality method has been documented in Ref. 23. The accuracy of the depletion calculation method and the effect of depletion uncertainty on $k_{\text {eff }}$ were evaluated in the current calculation report.

Specifically, this calculation provides the value for the penalty in waste package reactivity due to the bias and uncertainty associated with predicted SNF isotopic compositions for use in the development of loading curves for disposal of PWR SNF. For consistency with the previous loading curve analyses, ${ }^{18}$ this calculation used a PWR waste package model that is conservative with respect to criticality (see Sect. 7.3 and Sect. 7.1.1). The results were determined for PWR SNF assemblies with six combinations of initial enrichment and burnup characterizing data points in the proximity of the established loading curve for PWR SNF (see Sect. 7.3.1). Additional data points located slightly above and below the established loading curve were considered to evaluate the sensitivity of the results to burnup variation. The variation with time of the effect of depletion uncertainty on $k_{\text {eff }}$ and its impact on criticality safety were also evaluated.

The isotopic validation data for SCALE 5.1 consists of the M/C isotopic concentration values determined in Ref. 3 for 118 PWR fuel samples with initial enrichment ranging from 2.453 to 4.657 wt $\%{ }^{235} \mathrm{U}$ and burnup ranging from 7.2 to $70.4 \mathrm{GWd} / \mathrm{MTU}$. The isotopic bias and bias uncertainty for each burnup-credit isotope were determined in this calculation as the sample mean and the sample standard deviation, respectively, of the $\mathrm{M} / \mathrm{C}$ isotopic concentration values (see Sect. 6.3.1). The bias uncertainty was conservatively adjusted to account for uncertainties related to non-normality, dependence on burnup, and extension of the area of applicability of the validation data (see Sect. 7.2.1). The method used to propagate the isotopic composition bias and bias uncertainty to the $k_{\text {eff }}$ values for waste packages was Monte Carlo uncertainty sampling (see Sect. 6.3.2). This method provides a more realistic evaluation for the safety margin than the bounding method by crediting compensating reactivity effects of isotopic composition uncertainties on $k_{\text {eff. }}$.

The current calculation determined that the penalty in waste package reactivity due to the bias and uncertainty associated with predicted SNF isotopic compositions is 0.0229 (see Sect. 8). This value is intended to be used in the development of loading curves for disposal of PWR SNF and should not be generalized to other applications because it is dependent upon the specific application system. The work described in this calculation report was performed under the ORNL Quality Assurance Plan for the OCRWM and OCRWM Lead Laboratory Program, ORNL-OCRW-QAP-001 (Ref. 35). 



\section{REFERENCES}

1. Disposal Criticality Analysis Methodology Topical Report, YMP/TR-004Q, Rev. 02, Yucca Mountain Site Characterization Project, Las Vegas, Nevada (2003).

2. SCALE: A Modular Code System for Performing Standardized Computer Analyses for Licensing Evaluations, ORNL/TM-2005/39, Version 5.1, Vols. I-III, November 2006. Available from Radiation Safety Information Computational Center at Oak Ridge National Laboratory as CCC-732.

3. G. Radulescu, I. C. Gauld, and G. Ilas, SCALE 5.1 Predictions of PWR Spent Nuclear Fuel Isotopic Compositions, ORNL/TM-2010/44, Oak Ridge National Laboratory, Oak Ridge, Tennessee (2010).

4. X-5 Monte Carlo Team, MCNP-A General Monte Carlo N-Particle Transport Code, Version 5 -Volume I: Overview and Theory, LA-UR-03-1987 (April 24, 2003, Revised Oct. 3, 2005). Available from Radiation Safety Information Computational Center at Oak Ridge National Laboratory as CCC-730.

5. M. D. DeHart, A Stochastic Method for Estimating the Effect of Isotopic Uncertainties in Spent Nuclear Fuel, ORNL/TM-2001/83, Oak Ridge National Laboratory (2001).

6. Test Plan for: Isotopic Validation for Postclosure Criticality of Commercial Spent Nuclear Fuel, TP-OCRWM-LL-ORNL-02 Rev. 00, CN 01.

7. Calculation Packages, ORNL-OCRW-19.1, Rev. 03, CN 00.

8. Scientific Investigations, ORNL-OCRW-21.0, Rev. 03, CN 00.

9. Control of the Electronic Management of Data, ORNL-OCRW-23.0, Rev. 01, CN 01.

10. Software Control, ORNL-OCRW-19.0, Rev. 06, CN 00.

11. MCNP-YMP Software Verification Report for Linux_2, ORNL OCRW-SQA-015, Rev. 02, CN 00.

12. Standard Review Plan for Dry Cask Storage Systems, NUREG-1536, U.S. Nuclear Regulatory Commission, Washington, DC (1997).

13. SCALE-YMP Software Verification Report for Linux_2, ORNL OCRW-SQA-011, Rev. 03, CN 00 .

14. Quality Assurance Requirements and Description, DOE/RW-0333P, Rev. 21, U.S. Department of Energy, Office of Civilian Radioactive Waste Management, Washington, D.C. (2009).

15. Isotopic Generation and Confirmation of the PWR Application Model, CAL-DSU-NU-000004 REV 00A, Bechtel SAIC Company, Las Vegas, Nevada (2003).

16. Summary Report of Commercial Reactor Criticality Data for Crystal River Unit 3, TDR-UDCNU-000001 REV 02, Bechtel SAIC Company, Las Vegas, Nevada (2001). 
17. Data Qualification Report: Qualification of the Radiochemical Analysis Isotopic Validation Data, TDR-DS0-NU-000004 REV 00, Sandia National Laboratories, Las Vegas (2010).

18. CSNF Loading Curve Sensitivity Analysis, ANL-EBS-NU-000010 REV 00, Sandia National Laboratories, Las Vegas, Nevada (2008).

19. 10 CFR 961. 2008. Energy: Standard Contract for Disposal of Spent Nuclear Fuel and/or HighLevel Radioactive Waste.

20. NIST/SEMATECH e-Handbook of Statistical Methods, HTTP://WWW.ITL.NIST.GOV/DIV898/HANDBOOK/, April 2010.

21. R. E. Odeh and D. B. Owen, Tables for Normal Tolerance Limits, Sampling Plans, and Screening, Marcel Dekker, Inc., New York and Basel (1980).

22. E. M. Baum, H. D. Knox, and T. R. Miller, Nuclides and Isotopes, Chart of the Nuclides, $16^{\text {th }}$ Edition, Knolls Atomic Power Laboratory (2002).

23. G. Radulescu, D. E. Mueller, S. Goluoglu, D. F. Hollenbach, and P. B. Fox, Range of Applicability and Bias Determination for Postclosure Criticality of Commercial Spent Nuclear Fuel, ORNL/TM-2007/127, Oak Ridge National Laboratory (2007).

24. M. D. DeHart, "TRITON: A Two-Dimensional Transport and Depletion Module for Characterization of Spent Nuclear Fuel," Vol. I, Book 3, Sect. T1 in SCALE: A Modular Code System for Performing Standardized Computer Analyses for Licensing Evaluations, ORNL/TM-2005/39, Version 5.1, Vols. I-III, November 2006. Available from Radiation Safety Information Computational Center at Oak Ridge National Laboratory as CCC-732.

25. M. D. DeHart, "NEWT: A New Transport Algorithm for Two-Dimensional Discrete Ordinates Analysis in Non-Orthogonal Geometries," Vol. II, Book 4, Sect. F21 in SCALE: A Modular Code System for Performing Standardized Computer Analyses for Licensing Evaluations, ORNL/TM-2005/39, Version 5.1, Vols. I-III, November 2006. Available from Radiation Safety Information Computational Center at Oak Ridge National Laboratory as CCC-732.

26. S. M. Bowman, M. E. Dunn, D. F. Hollenbach, and W. C. Jordan "SCALE Cross-Section Libraries," Vol. III, Sect. M4 in SCALE: A Modular Code System for Performing Standardized Computer Analyses for Licensing Evaluations, ORNL/TM-2005/39, Version 5.1, Vols. I-III, November 2006. Available from Radiation Safety Information Computational Center at Oak Ridge National Laboratory as CCC-732.

27. I. C. Gauld, Strategies for Application of Isotopic Uncertainty in Burnup Credit, NUREG/CR6811 (ORNL/TM-2001/257), U.S. Nuclear Regulatory Commission, Oak Ridge National Laboratory (2003).

28. Calculation of Isotopic Bias and Uncertainty for PWR Spent Nuclear Fuel, CAL-DSU-NU-000001 REV A, Bechtel SAIC Company, Las Vegas, Nevada (2002). 
29. B. T. REARDEN, "TSUNAMI-3D: Control Module for Three-Dimensional Cross-Section Sensitivity and Uncertainty Analysis for Criticality," Vol. I, Book 2, Sect. C9 in SCALE: A Modular Code System for Performing Standardized Computer Analyses for Licensing Evaluations, ORNL/TM-2005/39, Version 5.1, Vols. I-III (November 2006). Available from Radiation Safety Information Computational Center at Oak Ridge National Laboratory as CCC-732.

30. B. N. Taylor and C. E. Kuyatt, Guidelines for Evaluating and Expressing the Uncertainty of NIST Measurement Results, NIST Technical Note 1297, U.S. Government Printing Office, Washington, DC (1994).

31. 21-PWR Waste Package with Absorber Plates Loading Curve Evaluation, CAL-DSU-NU000006 REV 00C, Bechtel SAIC Company, Las Vegas, Nevada (2004).

32. D. Boulanger, M. Lippens, L. Mertens, J. Basselier, and B. Lance, "High Burnup PWR and BWR MOX Fuel Performance: A Review of BELGONUCLEAIRE Recent Experimental Programs," ANS International Meeting on LWR Fuel Performance, Orlando, FL, USA, September 19-22, 2004.

33. G. Radulescu, D. E. Mueller, and J. C. Wagner, Sensitivity and Uncertainty Analysis of Commercial Reactor Criticals for Burnup Credit, NUREG/CR-6951 (ORNL/TM-2006/87), U.S. Nuclear Regulatory Commission, Oak Ridge National Laboratory (2007).

34. Standard Review Plan for Dry Cask Storage Fuel Systems, NUREG-1536, U. S. Nuclear Regulatory Commission, Washington, DC (1997).

35. Quality Assurance Plan for the Office of Civilian Radioactive Waste Management (OCRWM) and OCRWM Lead Laboratory Program at Oak Ridge National Laboratory, ORNL OCRW-QAP-001, Rev. 05, CN 00. 

APPENDIX A.

STATISTICAL CONCEPTS AND METHODS USED

IN VARIOUS ANALYSES 



\section{A.1 TOLERANCE-LIMIT FACTORS FOR ONE- AND TWO-SIDED INTERVALS}

Statistical tolerance limits are values such that the probability is equal to $\gamma$ that the limits include at least a proportion $p$ of the population. Tolerance-limit factors depend on the type of the distribution and on the sample size. The one-sided tolerance-limit factors, $k_{1}$, for normal distributions can be determined as shown in Eq. (A-1) (Ref. A-1, Sect. 7.2.6.3).

$$
\begin{gathered}
k_{l}=\frac{z_{1-p}+\sqrt{z_{1-p}^{2}-a \cdot b}}{a}, \\
a=1-\frac{z_{l-\gamma}^{2}}{1\left(N_{S}-l\right)} ; b=z_{l-p}^{2}-\frac{z_{l-\gamma}^{2}}{N_{S}},
\end{gathered}
$$

where

$$
\begin{aligned}
& z_{(1-p)}=\text { the critical value of the normal distribution that is exceeded with probability }(1-p) \\
& z_{(1-\gamma)}=\text { the critical value of the normal distribution that is exceeded with probability }(1-\gamma)
\end{aligned}
$$

The two-sided tolerance-limit factors, $k_{2}$, for normal distributions can be determined as shown in Eq. (A-2) (Ref. A-1, Sect. 7.2.6.3).

$$
k_{2}=\sqrt{\frac{\left(N_{S}-1\right)\left(1+\frac{1}{N_{S}}\right) z_{(1-p) / 2}^{2}}{\chi_{\gamma, N_{S}-1}^{2}}} .
$$

In Eq. (A-2), $\chi_{\gamma, N-1}^{2}$ is the critical value of the chi-square distribution, with degrees of freedom $N_{S}-1$, that is exceeded with probability $\gamma$, and $z_{(1-p) / 2}$ is the critical value of the normal distribution that is exceeded with probability $(1-p) / 2$.

Tolerance-limit factors for two-sided intervals (95\% certainty/68.27\% of the population) and one-sided intervals $(95 \%$ certainty $/ 95 \%$ of the population; $\mathrm{N}>50)$ were calculated in a Microsoft Office Excel application (see DVD/xls/validation.xls) using standard Excel statistical functions NORMSINV and CHIINV and the formulas shown by Eqs. (A-2) and (A-1), respectively, based on the procedure described in NIST/SEMATECH e-Handbook of Statistical Methods, Sect. 7.2.6.4 (Ref. A-2); whereas the tolerancelimit factors for one-sided intervals $(95 \%$ certainty $/ 95 \%$ of the population; $\mathrm{N} \leq 50)$ were taken from Ref. A-2.

\section{A.2 STATISTICAL SIGNIFICANCE OF TRENDING}

The hypothesis test presented in this section was used to identify the sets of $\mathrm{M} / \mathrm{C}$ isotopic concentration values that show significant dependence on sample burnup. In this hypothesis test, the normal distribution assumption is used to find significance levels. For the linear regression models, statistical significance of trending is determined by the test of hypothesis that the slope differs from zero, as described in Ref. A-3. 
The statistical model is a linear relationship between an independent variable predictor variable, $x$ (e.g., fuel burnup or initial enrichment) and the dependent variable, $y(x)$ (e.g., M/C isotopic concentration ratio):

$$
y(x)=\beta_{0}+\beta_{1} x+\varepsilon,
$$

where $\varepsilon$ is a random variable possessing a specified probability distribution with mean zero so that the expected value for $\mathrm{y}(x)$ is $E(Y)=\beta_{0}+\beta_{1} x$. Inferences concerning the parameter $\beta_{1}$ can be obtained using the test statistic shown in Eq. (A-3) that possesses a Student's distribution with $n$ - 2 degrees of freedom, where $n$ is the sample size:

$$
T=\frac{\hat{\beta}_{1}-\beta_{10}}{S \sqrt{c_{11}}}
$$

where

$\hat{\beta}_{l}=\frac{S_{x y}}{S_{x x}}$ is an unbiased, normally distributed estimator of $\beta_{1}$,

$\beta_{10}$ is a specified value of $\beta_{1}$, which is zero in the case of null hypothesis testing,

$S^{2}=S S E /(n-2)$,

$S S E=S_{y y}-\hat{\beta}_{1} S_{x y}$,

$c_{11}=\frac{1}{S_{x x}}$,

$S_{x x}=\sum_{i=1}^{n}\left(x_{i}-\bar{x}\right)^{2}$,

$S_{x y}=\sum_{i=1}^{n}\left(x_{i}-\bar{x}\right)\left(y_{i}-\bar{y}\right)$,

$\bar{x}=\frac{1}{n} \sum_{i=1}^{n} x_{i}$.

The Test of Hypothesis for $\beta_{1}$ is
$\mathrm{H}_{0}$ :
$\beta_{1}=0$
$\mathrm{H}_{\mathrm{a}}$ :
$\beta_{1} \neq 0$ (two-tailed rejection region)
Test Statistic:
$T=\frac{\hat{\beta}_{1}-\beta_{10}}{S \sqrt{c_{11}}}$
Rejection Region: $\quad|t|>t_{\alpha / 2}$ (two-tailed alternative), where $\alpha$ is the level of significance. 


\section{A.1 REFERENCES}

A-1. NIST/SEMATECH e-Handbook of Statistical Methods, HTTP://WWW.ITL.NIST.GOV/DIV898/HANDBOOK/, April 2010.

A-2. R. E. Odeh and D. B. Owen, Tables for Normal Tolerance Limits, Sampling Plans, and Screening, Marcel Dekker, Inc., New York and Basel (1980).

A-3. D. Sciff and R. B. D’Agostino, Practical Engineering Statistics, John Wiley \& Sons, Inc., New York, NY (1996). 

APPENDIX B.

VALIDATION OF THE MONTE CARLO UNCERTAINTY SAMPLING METHOD 

The purpose of Appendix B is to document the validation of the automated processes employed in this calculation, thereby demonstrating correct implementation of the Monte Carlo uncertainty sampling method (refer to Sect. 6.3 for method description). The application case used in support of the validation study is the PWR waste package containing SNF of $3.5 \mathrm{wt} \%{ }^{235} \mathrm{U}$ initial enrichment, $25 \mathrm{GWd} / \mathrm{MTU}$ burnup, and 5-year cooling time. The validation study addresses the following requirements for the successful implementation of the Monte Carlo uncertainty sampling method:

(1) generation of random numbers from the standard normal distribution;

(2) proper use of the generated random numbers to correct the predicted isotopic compositions for bias and bias uncertainty; and

(3) convergence of the $k_{e f f-M C}$ and $\Delta k_{\text {eff }-M C}$ values [see Eqs. (9) and (10), respectively, in Sect. 6.3].

An automated procedure named "kronossm" was executed within the SCALE code system to generate random numbers from the standard normal distribution and to adjust the predicted spent fuel compositions in accordance with Eq. (8). The kronossm executable compiled with INTEL FORTRAN 11.1.064 is provided in DVD/kronossm. A kronossm input file must contain the path of the kronossm executable, such as the following for a Linux system (see the *.inp files in DVD/MC.zip):

$=$ shell

In -s /scale/scale6.dev/Linux_x86_64/kronossm/kronossm

end

=kronossm

The results presented in this calculation report are not dependent upon the automated procedure that performed implementation of the Monte Carlo uncertainty sampling method. Other means that may be used to generate random numbers from the standard normal distribution include Excel and ORIGIN applications.

\section{B.1 GENERATION OF RANDOM NUMBERS FROM A STANDARD NORMAL DISTRIBUTION}

The procedure used to automatically generate random numbers from the standard normal distribution is described in Ref. B-1. It is based on the ziggurat method, the name being suggested by the shape of a single, convenient density that provides for both the fast and the slow parts of the generating process. The method leads to exceptionally fast algorithms for generating variates with decreasing or unimodal, symmetric density functions. The generated random numbers generally pass a normality test. For each MCNP calculation, 28 sets of 500 random numbers were generated. As demonstrated in DVD/opj/validation.opj, of the 28 sets of 500 random numbers, only one set of random numbers did not pass the Shapiro-Wilk normality test at the 0.05 significance level. Similarly, only 1 in 28 sets of 200 random numbers did not pass the Shapiro-Wilk normality test. The random numbers generated for use in each Monte Carlo simulation are available in the files *.output (see DVD/MC.zip).

\section{B.2 ADJUSTMENT OF THE PREDICTED SPENT FUEL ISOTOPIC COMPOSITIONS}

Five hundred MCNP input files specifying spent fuel compositions stochastically corrected for bias and bias uncertainty were created based on Eq. (8) (see Sect. 6.3.2) and the 28 sets of 500 random numbers generated. Correct implementation of Eq. (8) is demonstrated in DVD/xls/validation.xls, worksheet inputver, for several MCNP cases. The spreadsheet application used a set of 28 numbers randomly sampled from the standard normal distribution as described above and the bias and bias uncertainty values established for the SCALE 5.1 predictions for each burnup credit isotope (see Sect. 6.3.1) to determine new isotopic compositions in accordance with Eq. (8). The results of the spreadsheet application were 
then compared with the fuel isotopic concentrations existing in the corresponding MCNP input file. The comparison shows no difference between the isotopic concentration values determined by using the automated procedure employed and the Excel application. Similarly, correct implementation of Eq. 15 applicable to the bounding uncertainty method (see Sect. 6.4) is demonstrated in DVD/xls/validation.xls, worksheet input-ver.

\section{B.3 CONVERGENCE OF THE EXPECTED VALUES FOR $k_{e f f-M C}$ AND $\Delta k_{e f f-M C}$}

The Monte Carlo uncertainty sampling method is computationally intensive because of the large number of criticality calculations required. $k_{\text {eff }}$ bias uncertainty determined in this calculation report is based on a minimum of 200 MCNP calculations using isotopic concentrations randomly sampled from the normal distributions characterized by the mean and standard deviation values tabulated in Sect. 7.2.1, Table 9. A comparison between the statistical behavior of the quantities of interest $k_{\text {eff }-M C}$ and $\Delta k_{\text {eff }-M C}$ [see Eqs. (9) and (10), respectively] for 200 and 500 random cases is illustrated in Fig. B-1. As seen in the figure, approximately 200 random cases adequately ensure the convergence of both $k_{\text {eff }-M C}$ and $\Delta k_{\text {eff }-M C}$. Figure B-2(a) and (b) illustrate the histogram diagrams obtained for the $k_{\text {eff }}$ values based on 200 and 500 random cases, respectively. The $k_{e f f-M C}$ values based on 200 and 500 random cases were 0.9381 and 0.9368 , respectively, as compared to 0.9373 (best estimate $k_{\text {eff }}$ value) obtained by correcting the predicted isotopic composition for bias only. The $\Delta k_{\text {eff }-M C}$ values based on 200 and 500 random cases were 0.0118 and 0.0124 , respectively. The standard deviation of a MCNP $k_{\text {eff }}$ value was 0.0003 . 


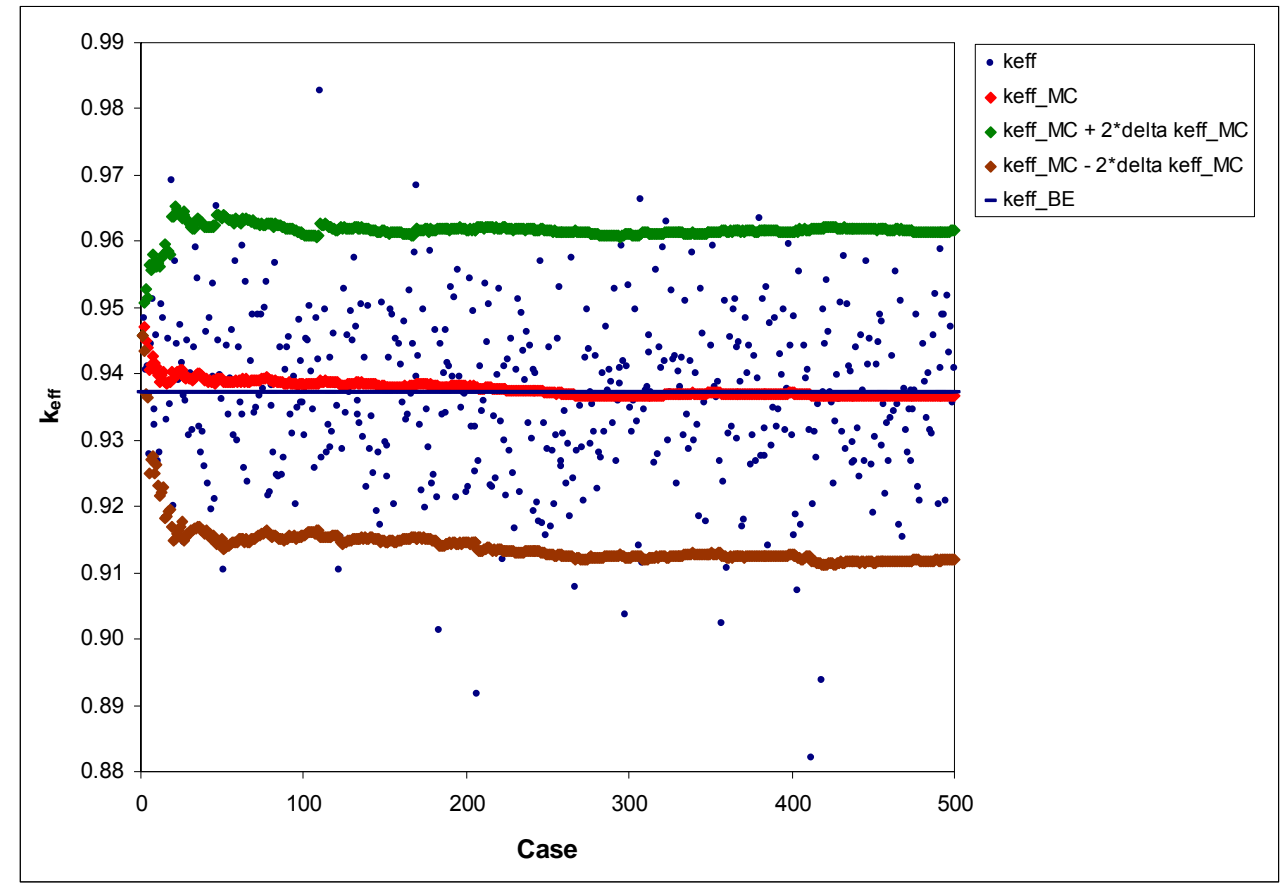

Fig. B-1. $\boldsymbol{k}_{\text {eff }-M C}$ and $\Delta \boldsymbol{k}_{\text {eff }-M C}$ convergence.

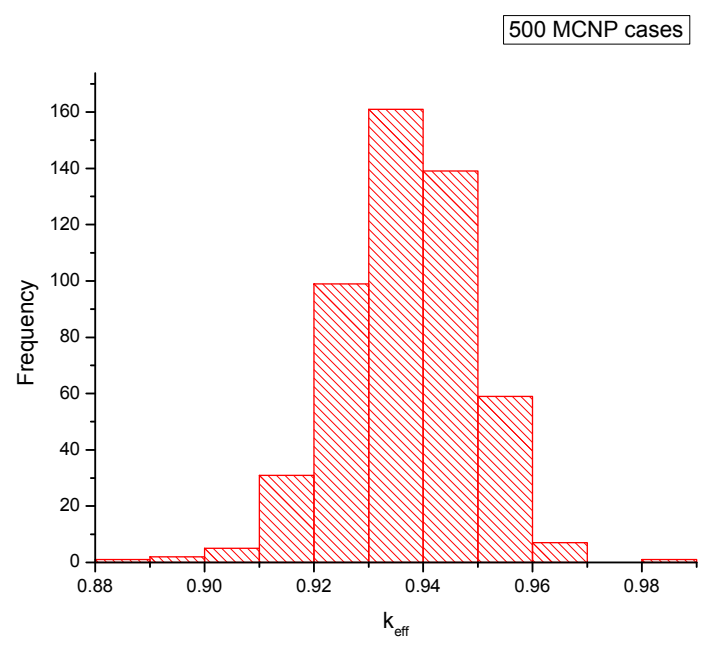

(a)

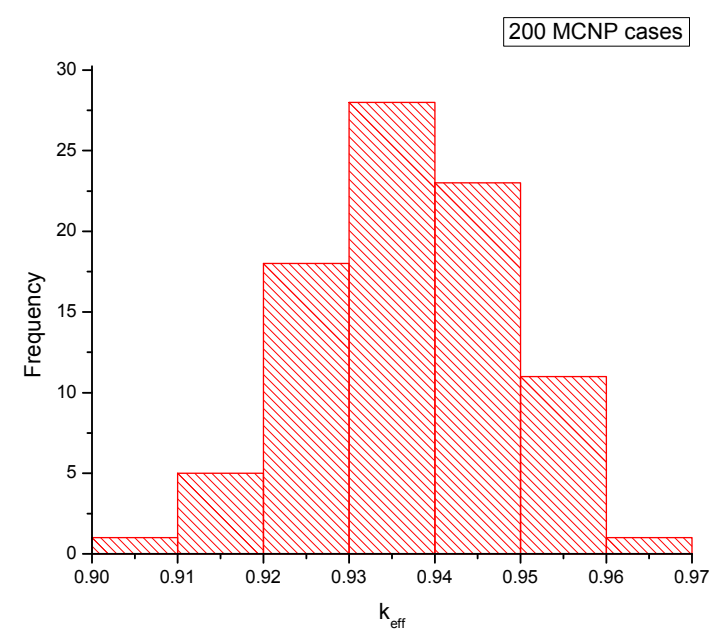

(b)

Fig. B-2. $k_{\text {eff }}$ frequency histograms from (a) 500 MCNP cases and (b) from 200 MCNP cases. 


\section{B.4 REFERENCES}

B-1. G. Marsaglia and W. W. Tsang, "A Fast, Easily Implemented Method for Sampling from Decreasing or Symmetric Unimodal Density Functions," Siam J. Sci. Stat. Comput. 5, 349-359, June 1984. 
APPENDIX C.

\section{ELECTRONIC DATA SPECIFICATIONS}



This appendix contains a listing and description of the files contained in the Digital Versatile/Video Discs (DVD-R format) that are attached to the calculation report Propagation of Isotopic Bias and Uncertainty to Criticality Safety Analyses of PWR Waste Packages. The operating system used to create the electronic data on the DVDs was Microsoft Windows XP Professional, Version 2002. The zip archives were created using standard Windows XP compress capabilities. The following process controls for storage and protection of electronic data apply.

Medium: $\quad$ DVD

Conditions: $\quad$ Fireproof cabinet kept at ambient temperature

Location: $\quad$ OCRWM QA Records, currently stored in Building 5700, Room H330

Retention Time: $\quad$ Lifetime

Security: $\quad$ Fireproof cabinet is locked

Access: $\quad$ Project manager and records custodian only

The attributes of the electronic files are as follows:

\begin{tabular}{|c|c|c|c|c|c|}
\hline File/folder name & $\begin{array}{l}\text { Size (bytes) } \\
\text { (on disk) }\end{array}$ & Number of files & File date & File time & Description \\
\hline \multicolumn{6}{|c|}{ DVD 1 of $2^{a}$} \\
\hline kronossm & $1,468,416$ & 1 & $06 / 22 / 2010$ & $1: 38: 47 \mathrm{pm}$ & FORTRAN executable for kronossm \\
\hline MC.zip & $526,270,464$ & 14,126 & $06 / 22 / 2010$ & $1: 27: 21 \mathrm{pm}$ & $\begin{array}{l}\text { Archive containing all kronossm and } \\
\text { MCNP input and output files for criticality } \\
\text { calculations }\end{array}$ \\
\hline \multicolumn{6}{|c|}{ DVD 2 of $2^{a}$} \\
\hline TRITON.zip & $276,850,688$ & 900 & $06 / 22 / 2010$ & $2: 06: 27 \mathrm{pm}$ & $\begin{array}{l}\text { Archive containing SCALE/TRITON input } \\
\text { and output files for depletion calculations }\end{array}$ \\
\hline ORIGEN.zip & $5,496,832$ & 36 & $06 / 22 / 2010$ & $2: 05: 16 \mathrm{pm}$ & $\begin{array}{l}\text { Archive containing SCALE/ORIGEN inpu } \\
\text { and output files for decay calculations }\end{array}$ \\
\hline xls & $9,668,608$ & 3 & $06 / 22 / 2010$ & $2: 11: 24 \mathrm{pm}$ & $\begin{array}{l}\text { Folder containing all Excel files used in } \\
\text { this calculation }\end{array}$ \\
\hline opj & $4,102,144$ & 2 & $06 / 22 / 2010$ & $2: 11: 24 \mathrm{pm}$ & $\begin{array}{l}\text { Folder containing all ORIGIN files used in } \\
\text { this calculation }\end{array}$ \\
\hline
\end{tabular}

${ }^{a}$ The DVDs were created on June 22, 2010, by G. Radulescu. 